\title{
سياسة الخوصصة وأثرها على بورصة الجزائر
}

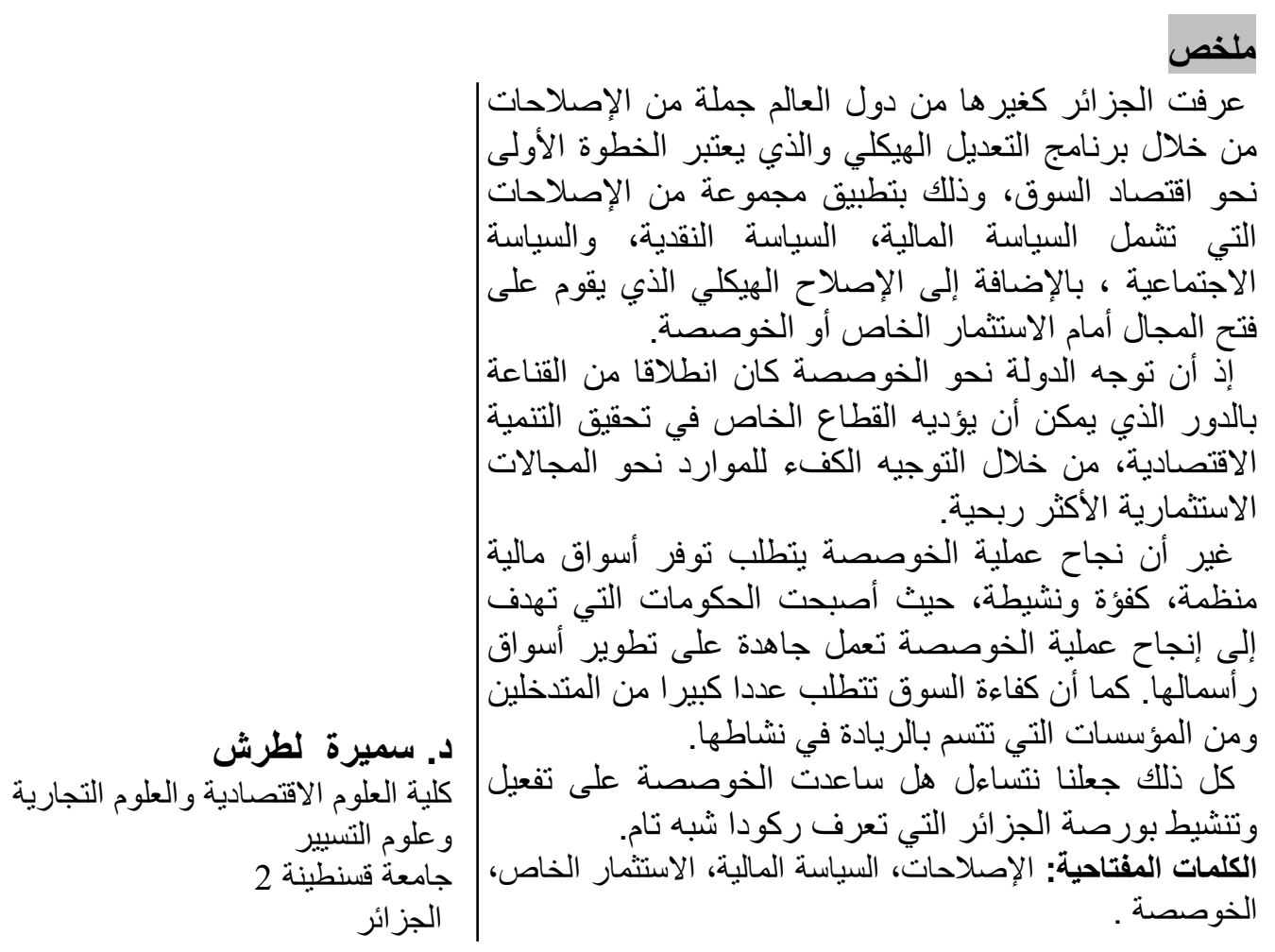

\section{Rقدئimé}

Cet article porte sur les moyens de paiement électroniques. On a dentamé notre étude par la électronique, puis on a abordé le service concepteur de cette الاقتصادي والاستقرار السياسي و الاجتماعي. dernière, et enfin répertorié les types de cartes concevables. Nous nous sommes egalement intéressés aux relations juridiques relatives à la

. de la carte de paiement électronique.

Mots clés : Réformes, Politique financière, Investissement privé, Privatisation. 


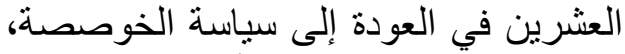

باعتبار ها إحدى الدعائم الأساسية للتصحيح

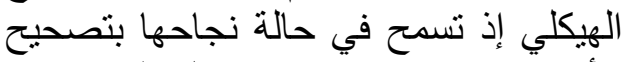

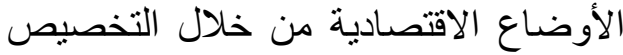

$$
\text { الكفه للموارد الاقتصادية. }
$$

لم تستغرق فكرة الخوصصة وقتا طويلا

\section{لنتنقل}

إلى دول العالم الثالث، من أجل النهوض باقتصاديات هذه الدول وتصحيح مختلف

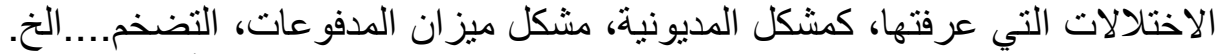
وقد كانت الجزائر من بين الدول التئي اعتمدت سياسة الخوصصة كأداة إصلاحية

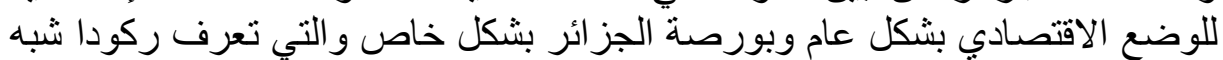
تام منذ نشأتها. فهل ساهمت عملية الخوصصة في تنشيط وتفعيل البورئه

$$
\text { I - الخوصصة }
$$

سنحاول أن نخصص هذا المحور لار اسة الخوصصة، مفهومها، دوافعها ،أساليب الخوصصة و أهدافها.

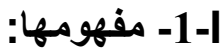

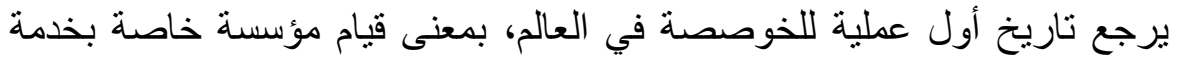

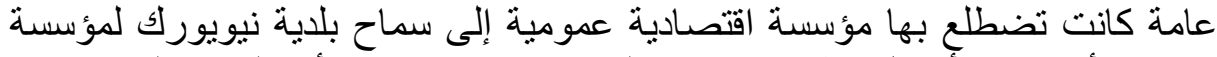

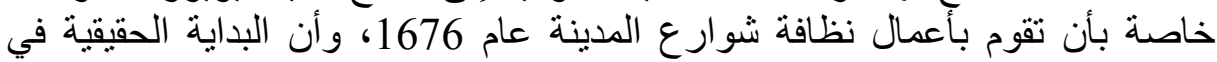

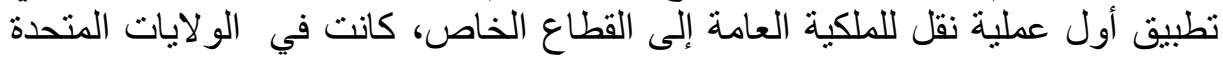

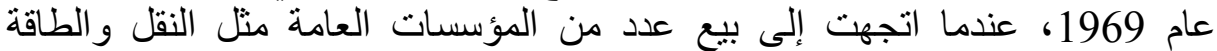

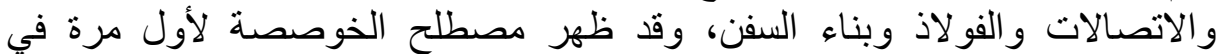

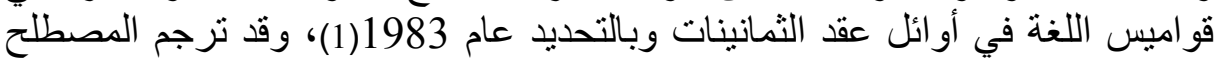
(privatisation)

التخصيص، الفردنة....الخ (2)

ولقد أعطيت عدة تعاريف لتوضيح مفهوم الخوصصة، وتختلف هذه التها التعاريف

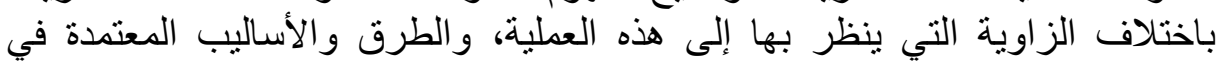
عملية الخوصصة في حد ذاتها.

"الخوصصة تعني توسيع الملكية الخاصة، ومنح القطاع الخاص دور منزايد داخل

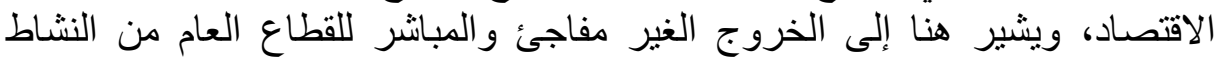

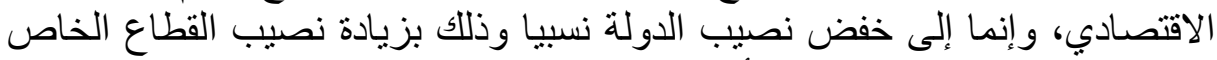

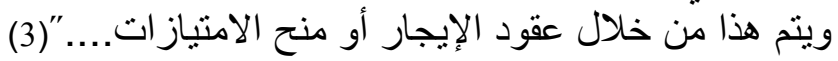


فالخوصصة تعني التقليل من دور المؤسسات الاقتصادية العمومية وزيادة

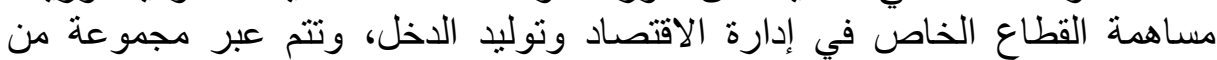

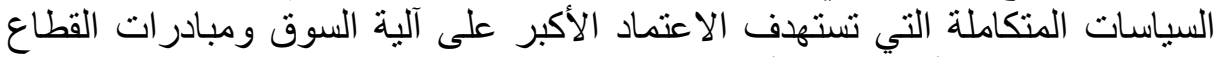

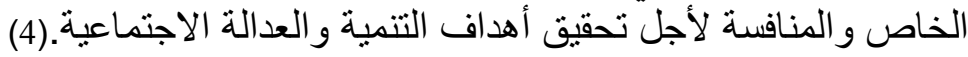

كما يعرفها البنك الدولي بأنها" زيادة مشاركة القطاع الخاص في إدارة ملكية

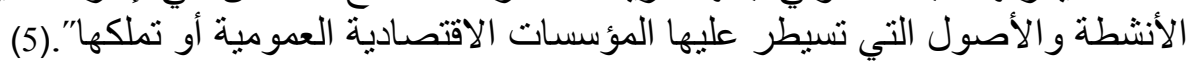

أما فيما يخص الجزائر فقد" وضعت الخوصصة في الجزائر موضع التصني التفيذ سنة

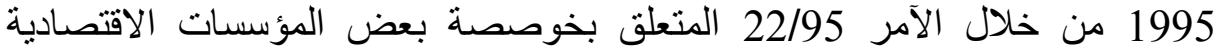
العمومية وركزت على قطاعي السياحة والتجارة، وكانت الدولة قد خصصت الأت 1222

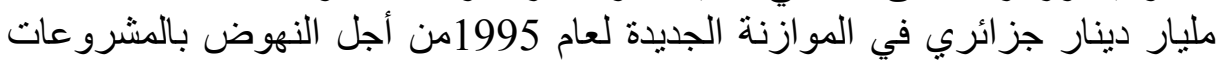

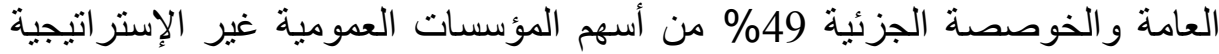

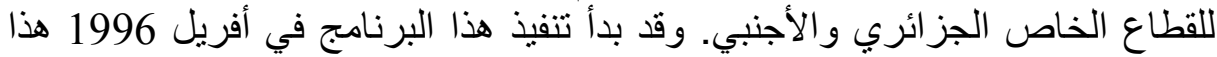
بمساندة البنك الدولي، حيث استهدف و التي تعمل معظمهاً في قطاع الخدمات (6).

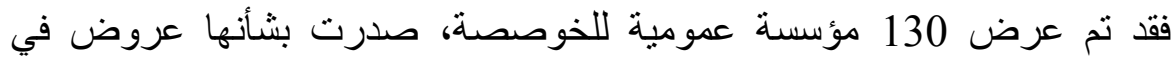

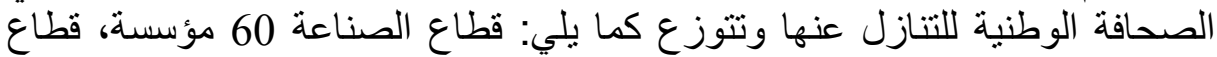

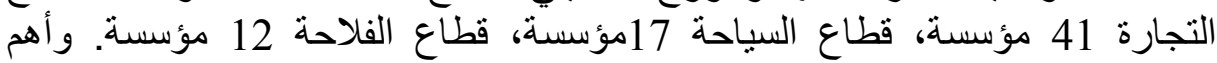

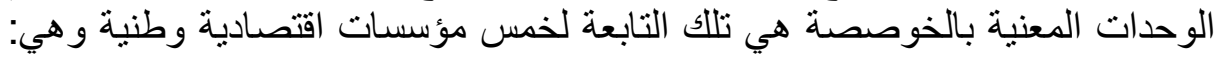
المؤسسة الوطنية للعصير والمصبرات ENAJUC، ENA المؤسية الوطنية للقطن و النسيج

ECOTEX الديوان الوطني للإنتاج المالي ENDPA، مؤسسة صيدال SAIDAL. لقد اقترح البنك العالمي خوصصة 300 مؤسسة عمومية وطنية (لقيع ربع العدد

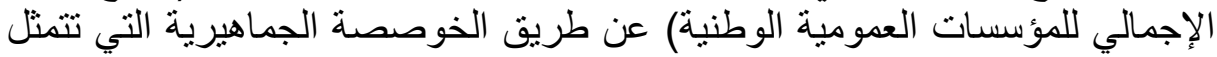

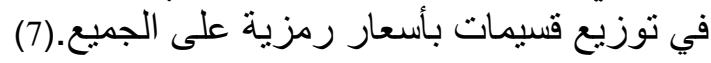

\section{-2- 2- دوافع الخوصصة}

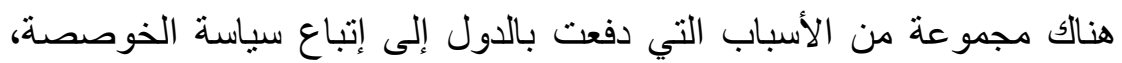
ويمكن إيجاز هذه الدو افع في مجمو عتين، دو افع داخلية ودو افع خارجية الأبية.

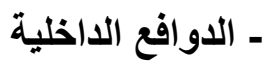

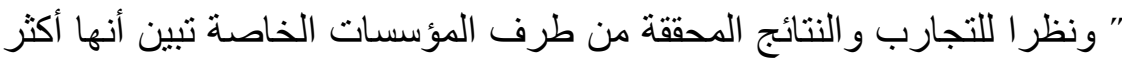

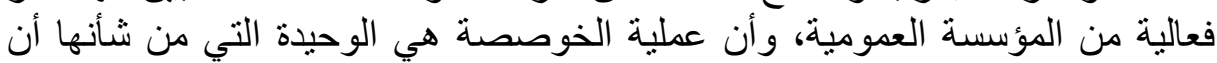

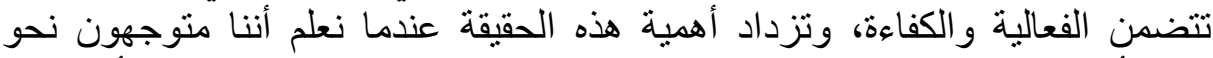

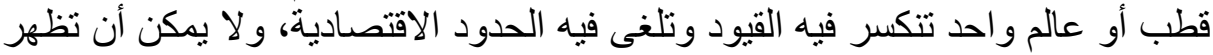

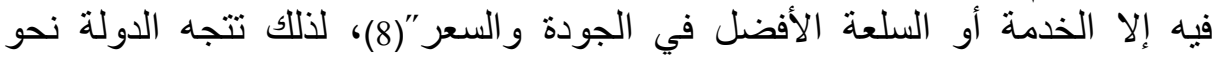


الخوصصة من أجل التقليل من حجم الأعباء الملقاة على عاتقها ، فهي بمنحها

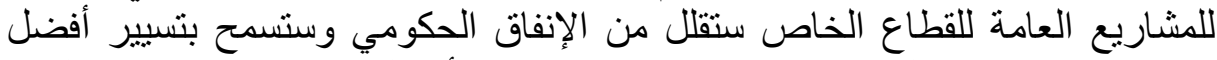

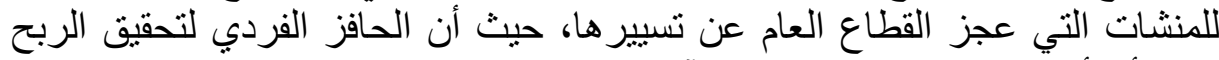
من شأنه أن يرفع من كفاءة هذه المنشآت العات

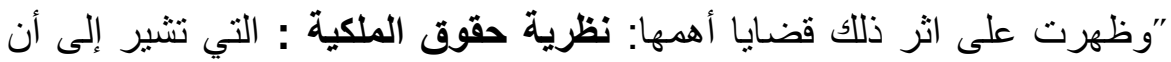

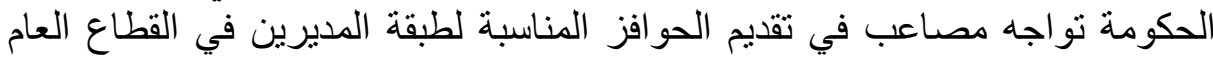

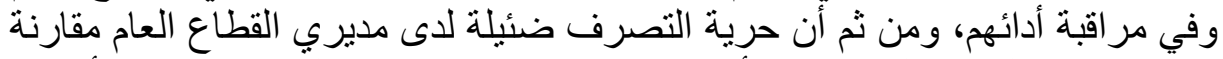

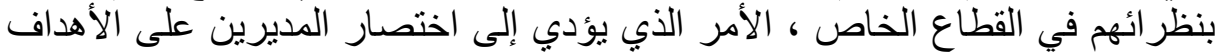

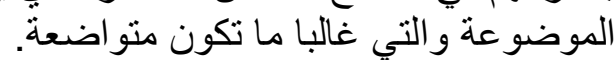

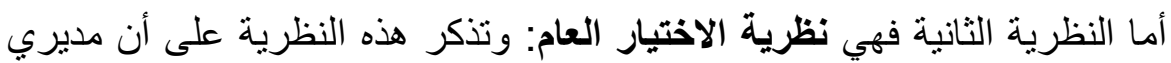

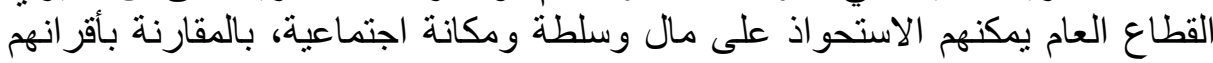

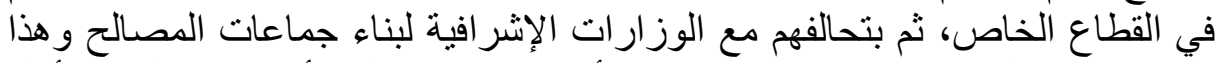

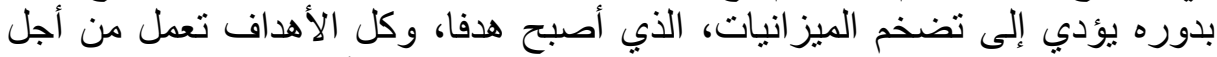

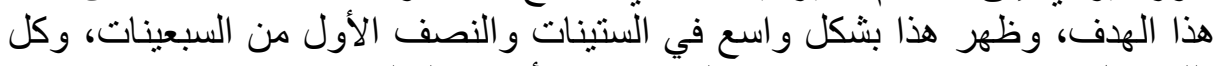

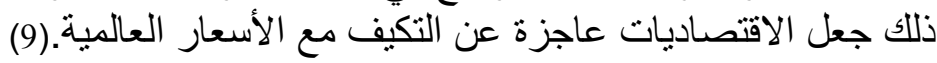

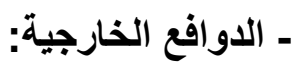

ترتكز هذه الدوافع بصورة أساسية على تدخلات المؤسسات الدولية، من خلال

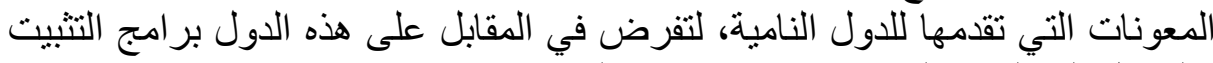

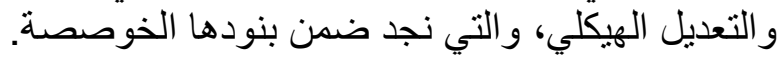

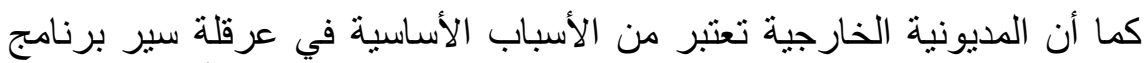

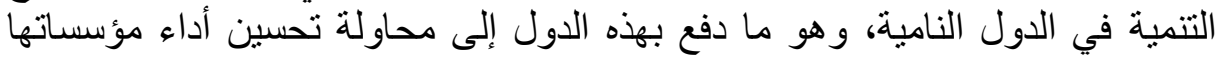

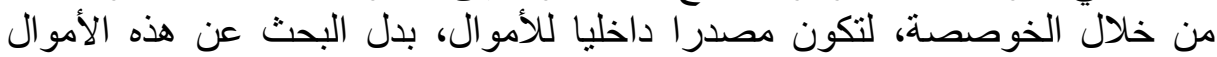
خارج حدود الدولة وما ينتج عنه من تبعية و غير ها.

و عليه يمكننا تلخيص أسباب الخوصصة في الجز ائر في العو امل التالية:

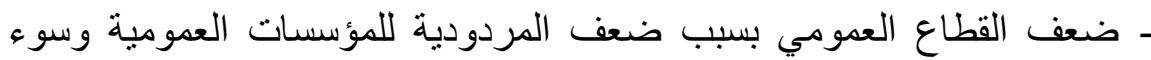

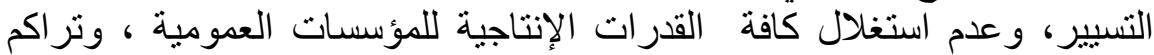

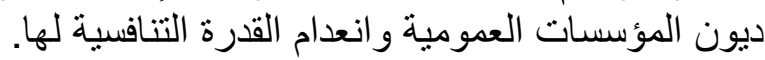
- تندرج الخوصصة ضمن برنامج التكييف والتعدئ التعديل الهيكلي، استجابة لتقديم المساعدات المالية من صندوق النقد الدولي والبنك العالمي وهذا ضمن سياسة

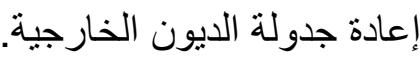
- إثقال كاهل الخزينة العمومية التي كانت تغطية التغي وتمول عجز المؤسسات العمومية، خاصة بعد انخفاض أسعار البترول سنة 1986، وبالتالي لم تسنطع 
الخزينة العمومية تحمل أعباء هذه المؤسسات إذ بلغت فاتورة التطهير المالي 800

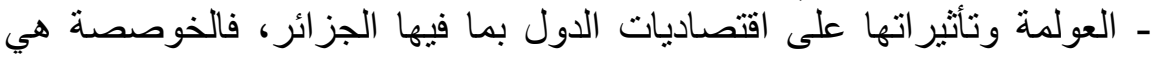
الطريق الوحيد للاندماج في الاقتصاد العادي العالمي.

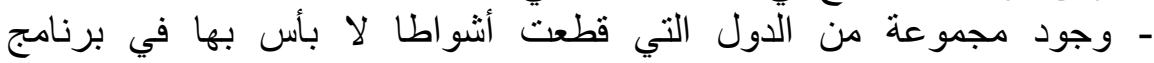

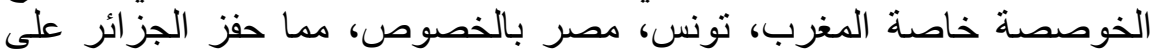
انتهاج نفس المسار بالرغم من أن الاقتصاد الجزائري ييقى له خصوصن خصوصيته، حيث

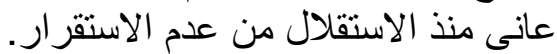
- ارتفاع معدلات التضخم الاستهلاكي بسبب تدهور الإن القطاع العمومي وعجزه عن الإنتاج. (10) (10)

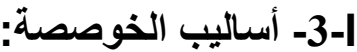

تتباين الأساليب المعتمدة في الخوصصة من دولة إلى أخرى، وهذا تبعا لإنة لعدة

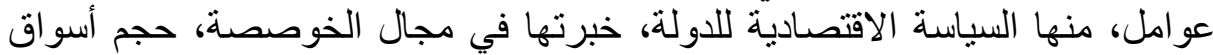

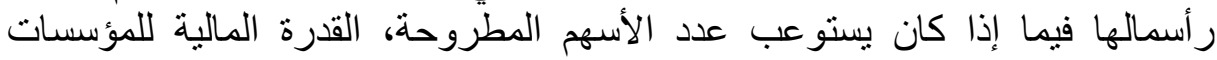

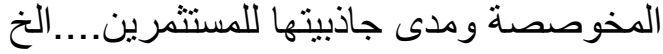

وفي هذا الإطار يمكننا حصر أساليب الخوصصة فيما يلي:

\section{|-1-3- الطرح العام للأسهم:}

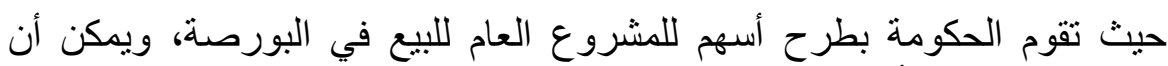

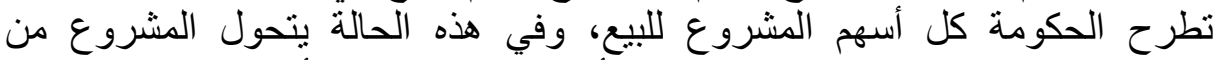

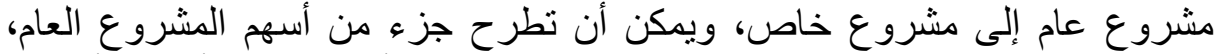

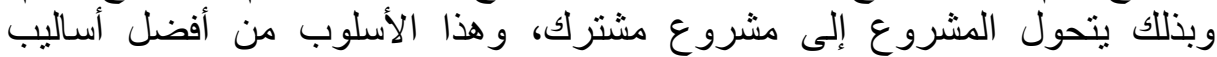

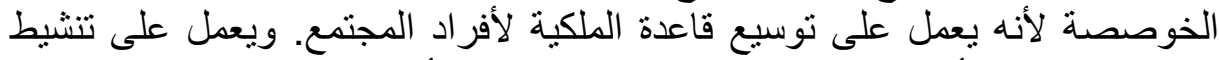

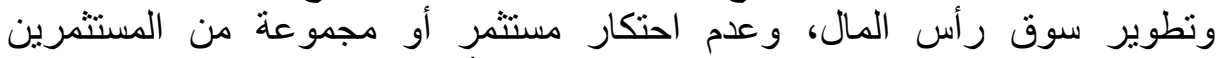

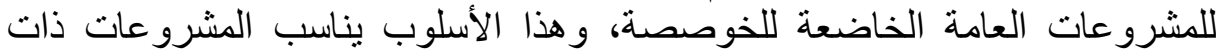
(11). الحجم الكبير

\section{|-2-3- الطرح الخاص للأسهم:}

يتم بيع المؤسسة هنا لصالح فئة خاصة من المستثرين وذللك بإتباع طريقة

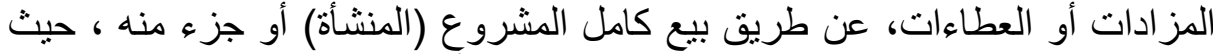

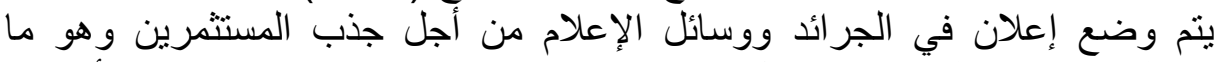

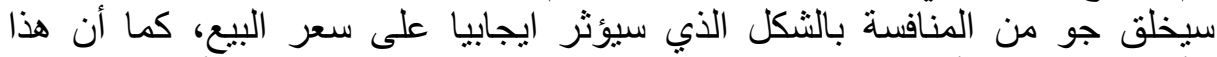

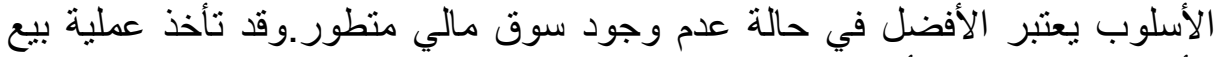
الأسهم للخو اص عدة أنثكال هي: ـ الاقتناء المباثر (الاكتساب) من طرف مؤسسة أخرى خاصة أو مختلطة. 
- بيع حصة من الأسهم لصالح مجموعة معينة قبل أو في نفس الوقت مع بيع الأسهر

(12). للجمهور من من

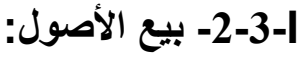

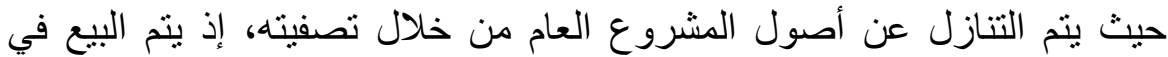

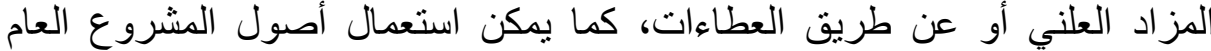

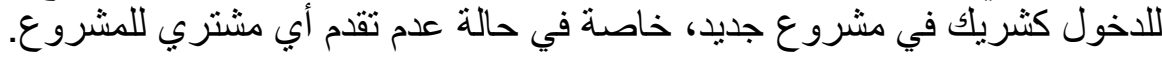

|-4-3- إتاحة فرص لنمو الاستثمارات الخاصة داخل المشروعات المشتركة

هنا تلجأ الحكومة إلى إتاحة الفرص لر أس المال الخاص في المساهمة في رأسمال

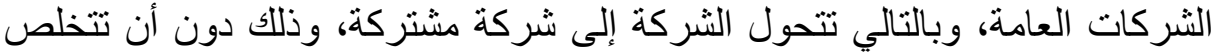

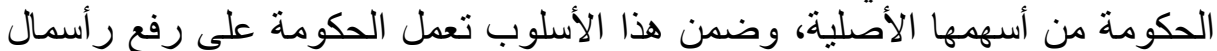
الثركة، وهذا الأسلوب يتلائم مع الشركات التي تكمن مشاكلها في التمويل بصفي رفئ

(13). أساسية. (13)

\section{|-5-3-3- البيع للعاملين أو الإدارة:}

يقصد بشر اء الإدارة للشركة قيام مجمو عة صغيرة من المديرين بالسيطرة و التحكم

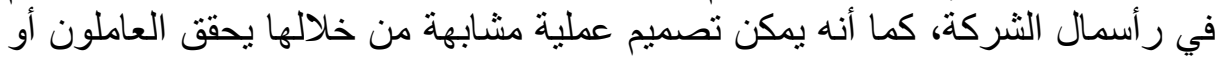

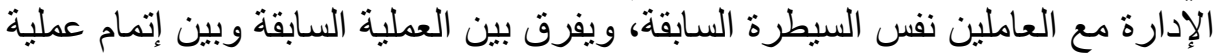

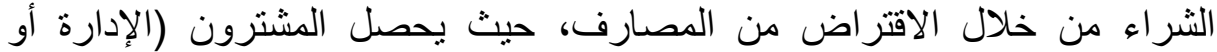

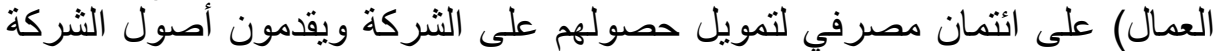

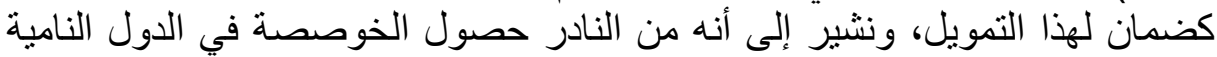

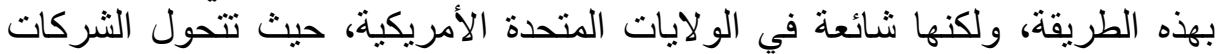
المساهمة إلى شركات خاصة.

وبالرغم من أن لهذه الطريقة مزايا كونها تجعل العاملين والإدارة يشعرون أنهم

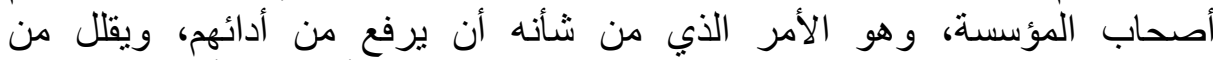

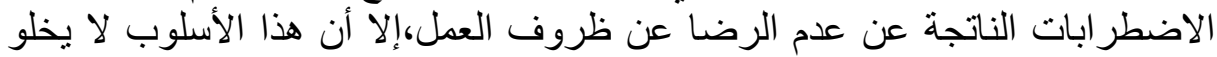

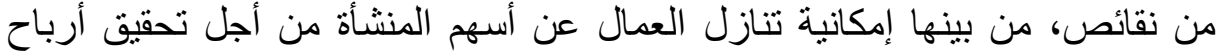

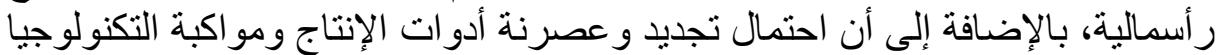

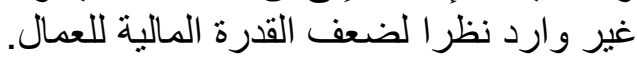

|-3-3- نظام مقايضة الديون بأسهم في مشروعات عامة

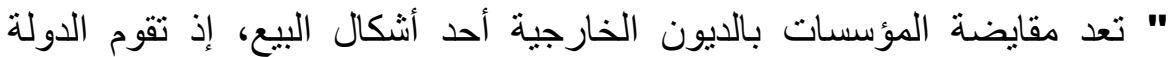

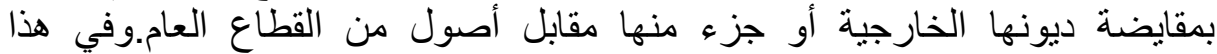

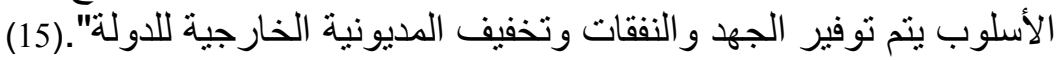




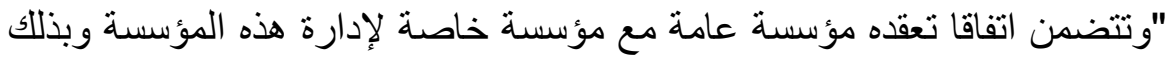

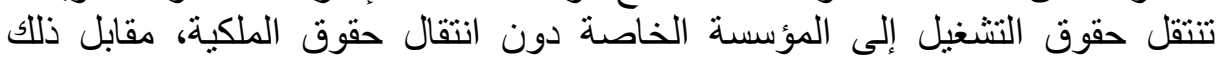

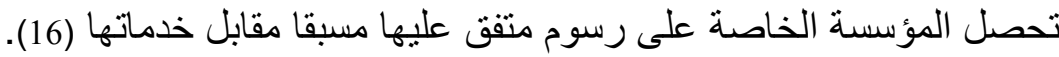
هذا بالنسبة لعقد الإدارة أما بالنسبة لعقد الإيجار فيتم من خلال تأجير أصول الصول الإنها

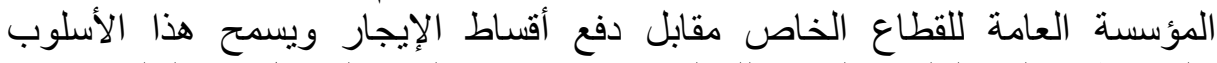

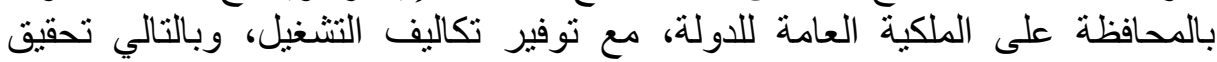

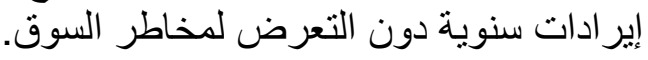

\section{|-8-3- نظام الكوبونات لمشاركة الطبقات محدودة الدخل:}

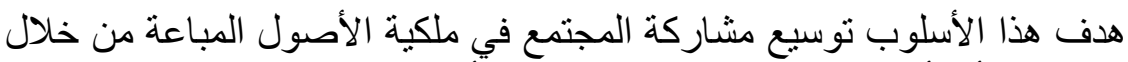

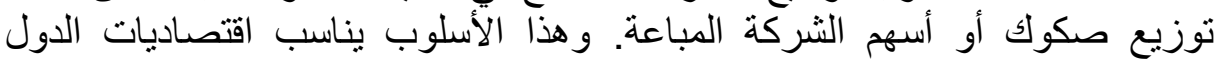

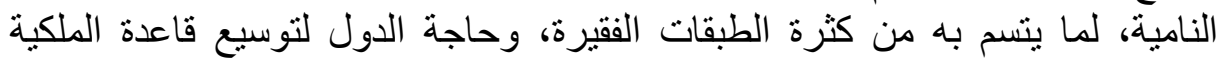

ومساعدة الطبقات الفقيرة. (17)

\section{|- - - - - أهداف الخوصصة}

إن عجز المؤسسات العمومية عن أداء الدور الموكل لها، ساهم في تحويل الاهنمام

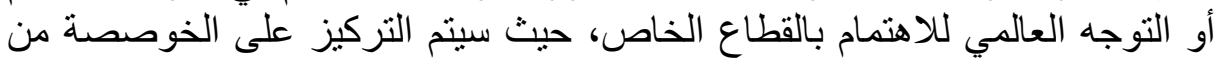

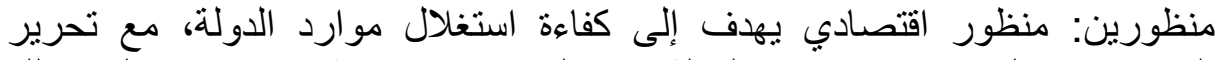

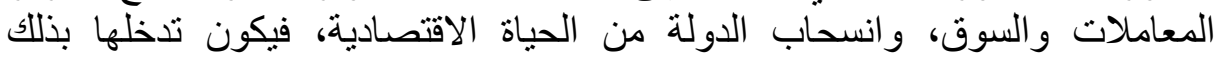
محصور فقط بالحالات الطارئة.

ومنظور سياسي يحدد إطار ا خاصا لتدخل الدولة ليشمل الخدمات العامة، الأمن،

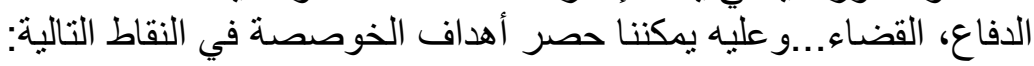

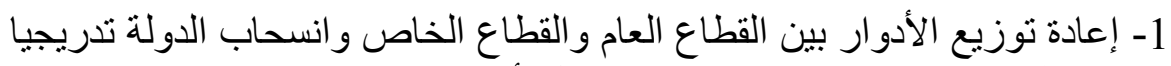

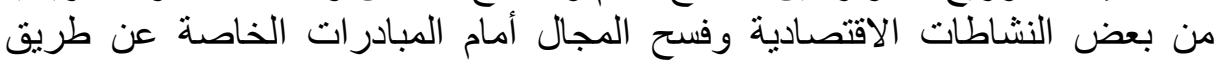

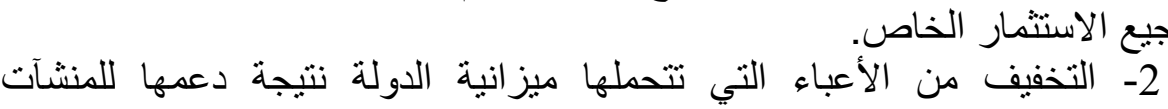

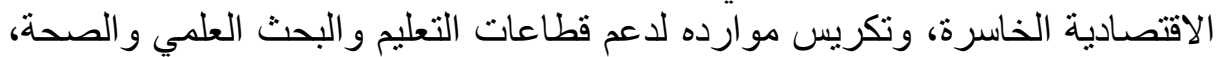

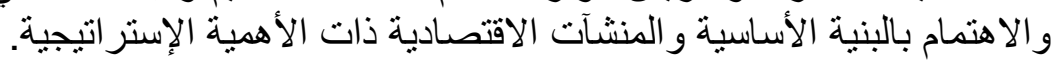

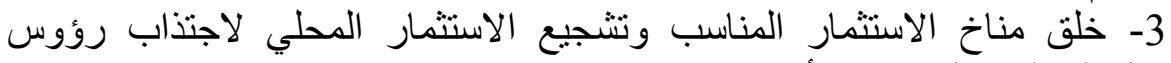
الأمو ال المحلية والعربية والأجنية الأنبية 4- تشجيع وتعزيز الكفاءة الاقتصادية عن طريق تعزية الاديز الأسو اق المالية و المنافسة.

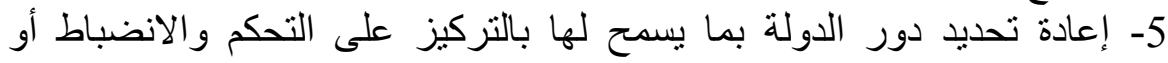

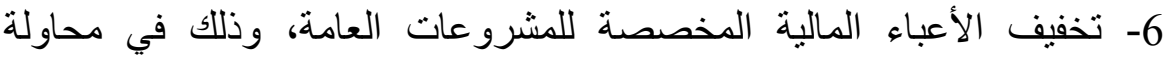
الإدارة. للوصول إلى ضوابط مالية واستقر ار على المستوى الكلي للبنيان الاقتصادي. 
7- أخفيف حدة الديون العامة.

8- تحرير الموارد المالية المحدودة في الدولة، وذلك لتمويل قطاعات أخرى مثل التعليم و الصحة. 9- خلق أو نشوء استثمار جديد متضمنا الاستثمار الأجنبي الخاص. 10 - تعبئة الموارد المحلية للتنمية.

11 - 11- توسيع قاعدة الملكية. 12- إثر الث العمال في الملكية أو التسيير، بالثكل الذي يحفز العمال أكثر ويحسن 13- تلبية حاجات المجتمع وذللك بتوفير منتجات ذات جودة عالية وبسعر أقل من أدائهم. - من 14 - تنشيط وتطوير أسو اق رأس المال.

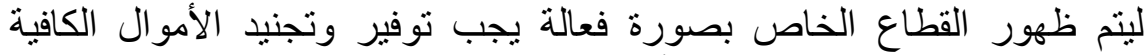

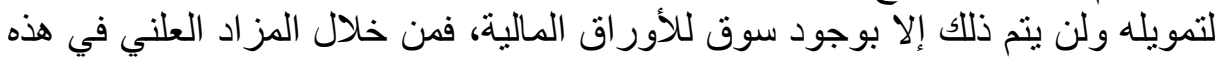

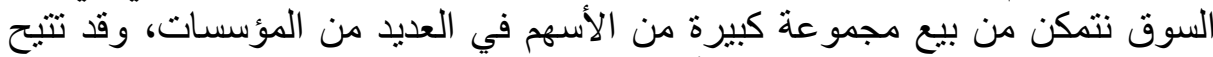

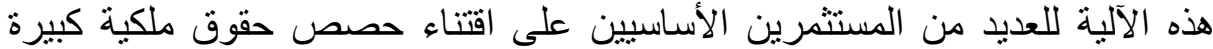
تمكنهم من السيطرة على إدارة الثركات المطروحة الفئ للخوصصة. أما عملية الاكتتاب

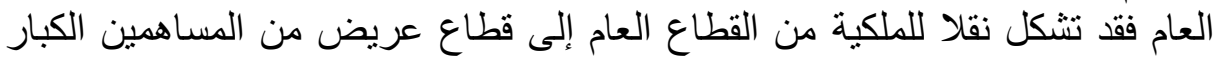

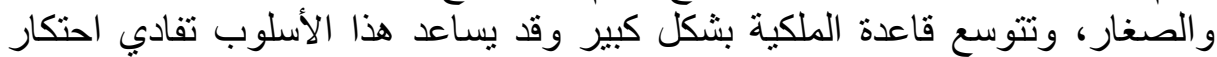

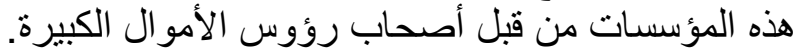

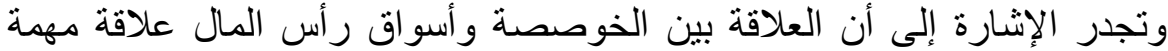

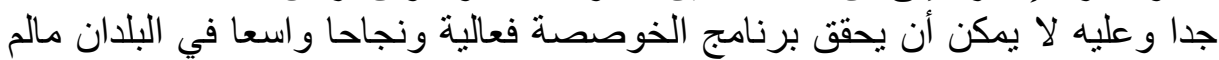
يتم تطوير أسو اق المال وذللك للأسباب التالية: - يصعب على المؤسسات العموية المعروضة للخوصصة أن تبيع أسهمها

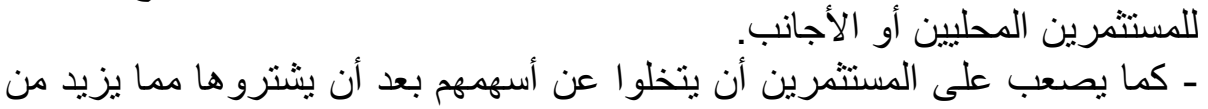

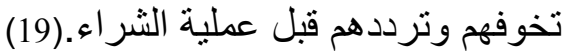

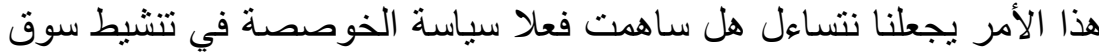

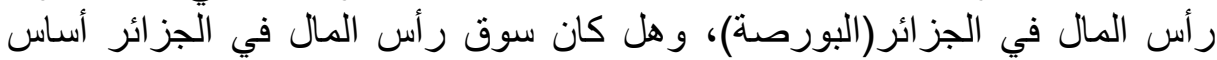

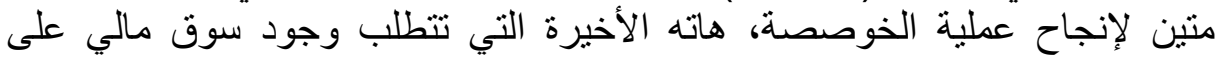

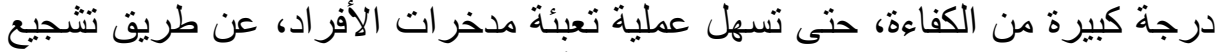

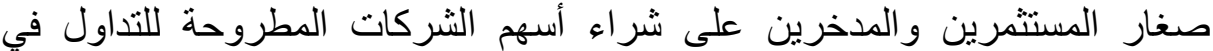

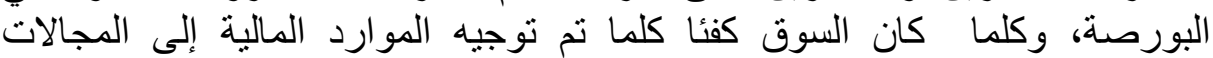

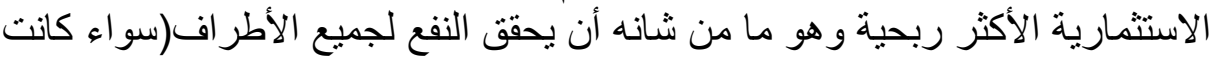
مؤسسات طرحت أور اقها المالية للتداول أو مستثمرين في هذه الأوراق المالية). 
سنخصص هذا العنصر لدر اسة بورصة الجزائر من حيث النشأة، التطور، شروط

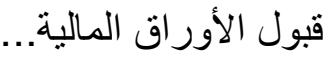

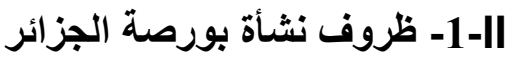

تعتبر سنة 1986 سنة التحول في الاقتصاد الجزائري، إذ أنه اعتبارا من هذه أنه التها

السنة عرفت الجزائر مجموعة من الإصلاحات، هاته الأخيرة التي جاءت كنات كنتيجة

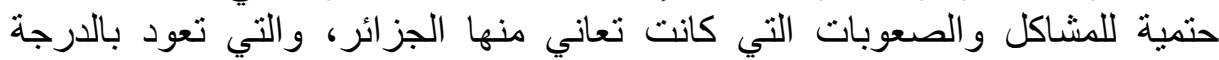

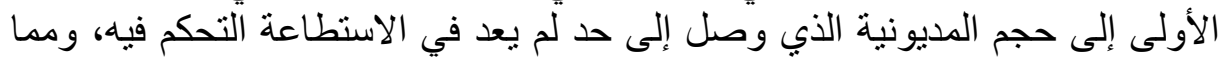

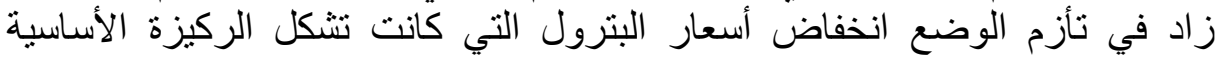

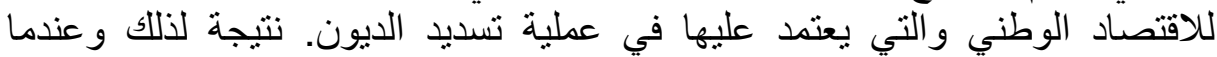

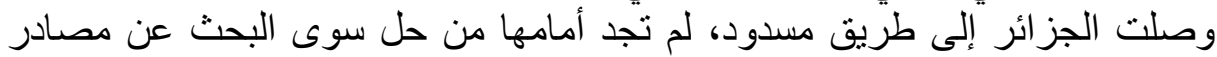

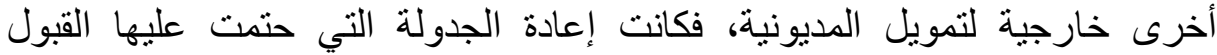

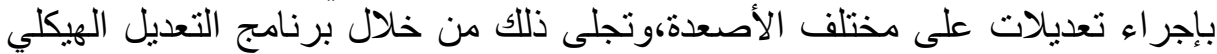

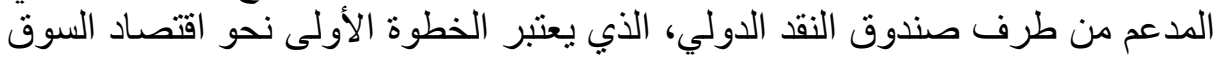

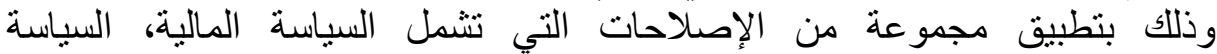
النقدية،والسياسة التجارية، بالإضافة إلى الإصلاح الهيكلي الذي يقوم على فتح الإلح الهجال أمام الاستثمار الخاص و الخوصصة.

وقد سبق ذلك إصدار مجموعة من القوانين، وعليه يمكن اعتبار سنة1986 بداية

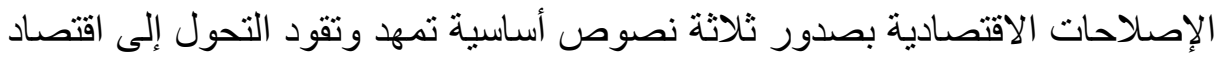

ـ قانون 12-86 المؤرخ في 1986/08/19 المتعلق بنظام القروض والبنوك.

ـ قانون88/ 16 المؤرخ في 1988/01/12 المتعلق باستقلالية المؤسسات.

ـ قانون 10/90المؤرخ في 1990/04/14 المتعلق بالنقد والقرض.

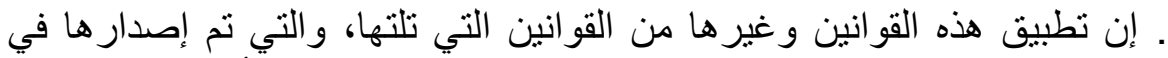

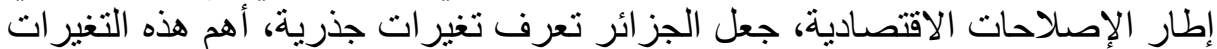

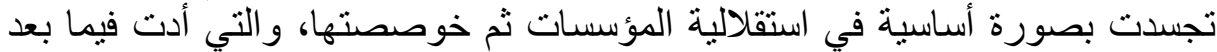

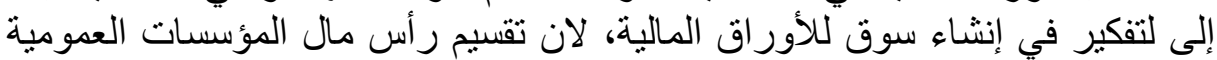

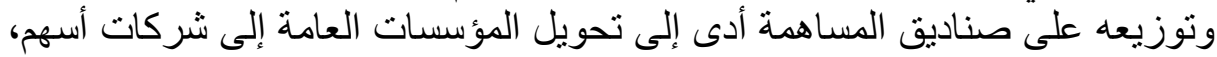
الأمر الذي استلزم إنشاء سوق للقيم المنقولة تتداول فيه الأوراق المالية لثركات

ـ لذلك صدر المرسوم التنفيذي رقم 91-169 في 28 ماي1991 لتنظيم المعاملات 
الخاصة بالقيم المنقولة، هذا المرسوم الذي استمد أحكامه من القانون 88-04، الصادر في 1988 حيث عرف هذا المرسوم القيم المنقولة بأنها كل منتوج مالي قابل للتداول

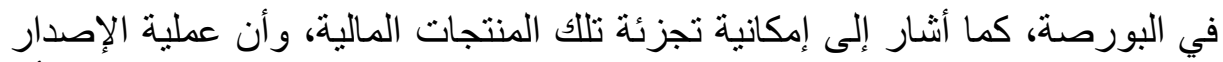

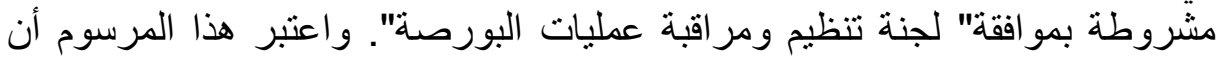

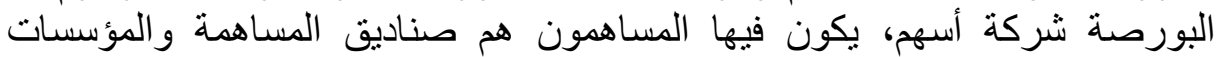

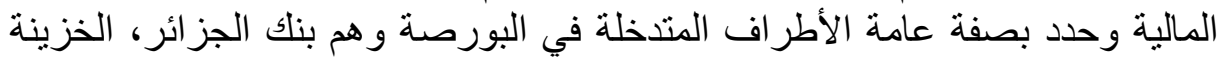
العامة، الوسطاء، المر اقب.

ثم في نفس اليوم صدر المرسوم 91-70 الذي حدد أنواع القيم المنقولة وشروط

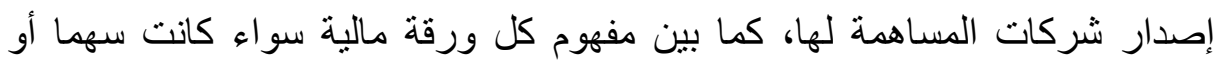

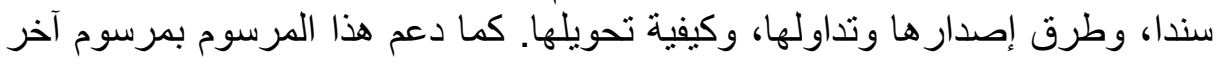
يحمل الرقم 91-171‘(20) صدر في نفس اليوم ويتعلق "بلجنة تنظيم ومر اقبة عمليات البورصة"، حيث حدد وظائفها وبين أنها تتكون من خمسة أعضاء وهم وهم الرئيس ونائبه

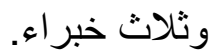

وفي 25 أفريل 1993 صدر المرسوم رقم 93-08 المعدل والمتمم للقانون

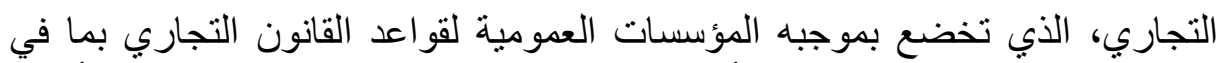
ذلك إمكانية إثهار إفلاسها إذا ما أخلت بالتز اماتها، كما تعرض التهات هذا المرسوم للأحكام المتعلقة بشركات المساهمة.

صدر كذلك مرسوم آخر في 23ماي 1993 وهو المرسوم رقم 93-10 المتعلق

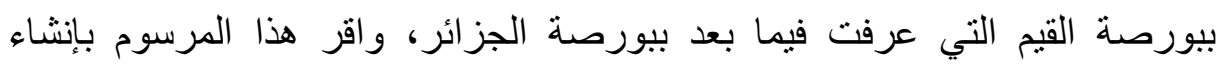

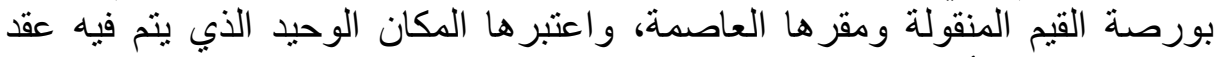

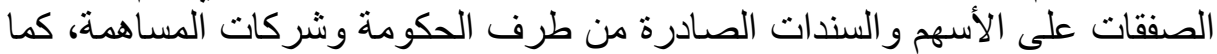
أقر بتبعية الهيئتين التاليتين للبوراتهة:

ـ لجنة تنظيم ومر اقبة عمليات البورصة (COSOB) - شركة تسيير بورصة وميم القيم (SGBV).

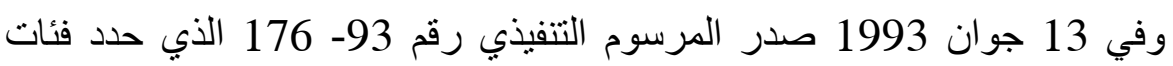

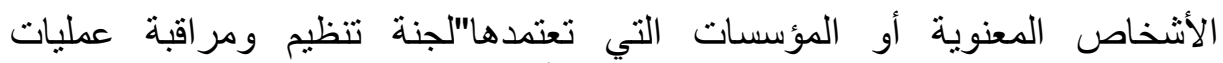
البورصة" كوسطاء، وهي البنولك، شركات التأمين،صناديق المساهمة التهني التي حلت في سبتمبر 1995.

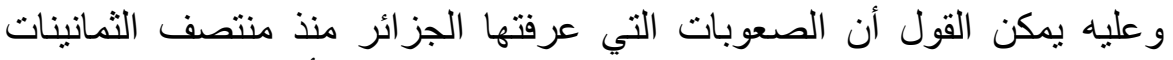

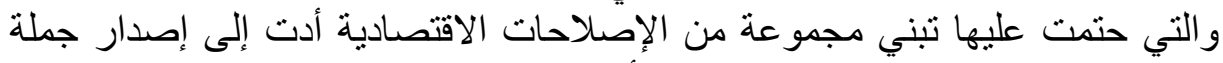

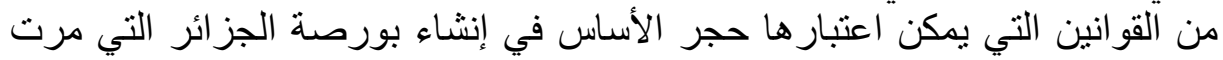


بمر احل يمكن إيجاز ها في الآتي:

||-2- مراحل إنشاء بورصة الجزائر

يمكن حصر المراحل التي مر بها إنثاء بورصة الجناء الجزائر في المر احل التالية:

أ. المرحلة الأولى(1990-1992):

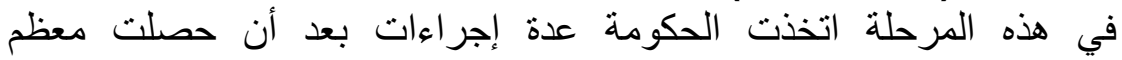

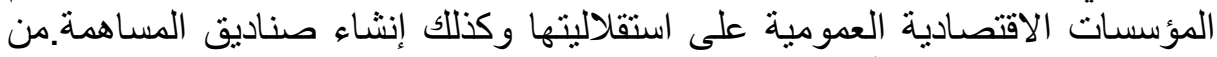
جملة هذه الإجراءات أنشئت مؤسسة دعيت "شركة القيم المنقولة" (svm) ومهمتها تشبه إلى حد بعيد مهمة البورصة في الدول العظمى،(21) لقد تأسست هذه الثركة الثركة

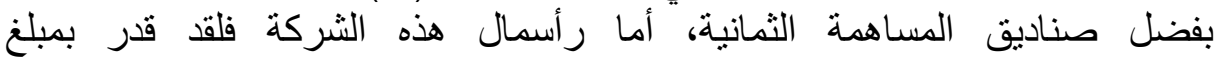

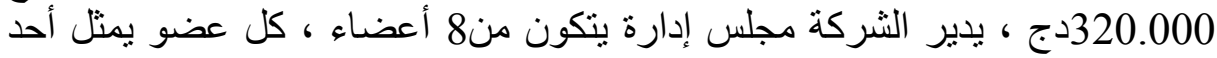

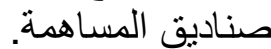
ب- المرحلة الثانية (بتثاء من 1992:

لقد مرت الثركة بفترة حرجة ناجمة عن ضعف رأسمالها الاجتماعي والدور الغير

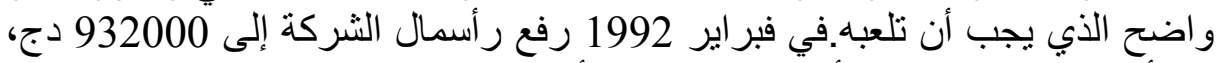

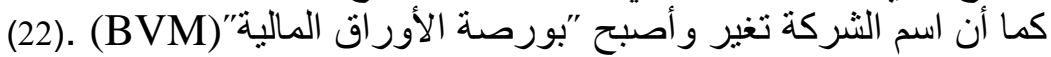

\section{ج- المرحلة الثالثة ابتأعا من 1997}

أنشئت شركة إدارة بورصة القيم بتاريخ 25 ماي 1937 مات 1997 وفقا للمرسوم التشريعي

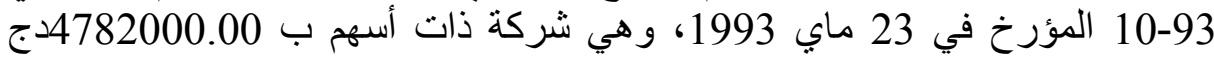

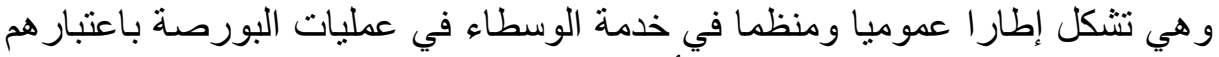

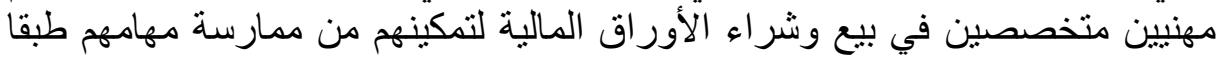

للقو انين و التنظيمات المعمول بهين

\section{* الأعضاء المؤسسون لشركة تسيير بورصة القيم:}

البنوك الوطنية: BDL , BEA, BADR ,BNA ,CPA ,CNEP, CNMA

شركات التأمين: SAA, CAAT, CCR, CAAR

بنك خاص: UNION BANK

* المساهمون في رأس المال:

بنك التنمية المحلية، البنك الجزائري الخارجي، بنك الفيلاحة والتئية التنمية الريفية، القرض الثعبي الجزائري، البنك الوطني الجزائري، الصندوقي، الوني، الوطني للادخار و التوفير - بنك.

- مهام شركة إدارة بورصة القيم: 
تأخذ شركة إدارة بورصة القيم على عاتقها القيام بالمهام التالية :

ـ التنظيم العملي لإدراج الأوراق المالية في البورصة و التنظيم الفعلي لحصص التداول في البورصة. ـ تسيير نظام التداول و التسعيرة.(23) - نشر المعلومات المتعلقة بالمعاملات في البورة فئة وإصدار النشرة الرسمية للتسعيرة. (24)

|I-3- شروط قبول الأوراق المالية للتداول في بورصة الجزائر:

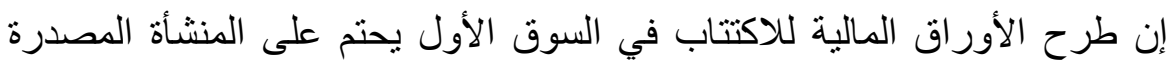

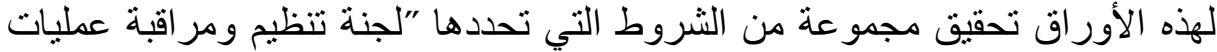

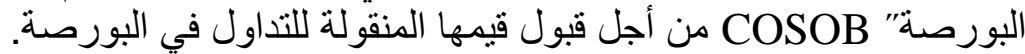

\section{أـ الإطار العام لقبول القيم المنقولة للتداول في البورصة فئل}

استنادا لما جاء في دليل لجنة تنظيم ومراقبة عمليات البورصة، فالن الفئ الفكرة

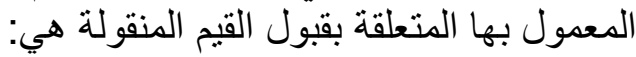

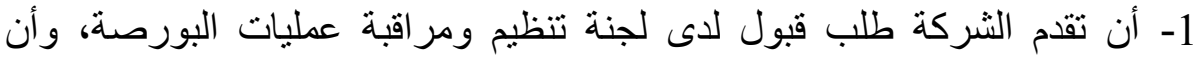

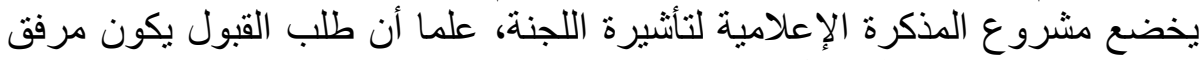

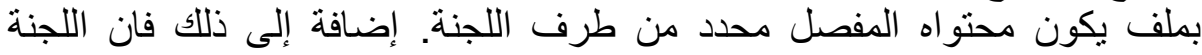
تراقب مشروع المذكرة الإعلامية حسب الإجراء المحدد لمنح التأثيرة عند إصدار

$$
\text { القيم المنقولة. }
$$

2- على الثركة أن تعين وسيط في عمليات البورصة (IOB) يكون مكلف بالمساعدة

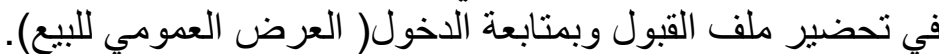

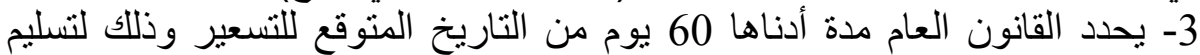

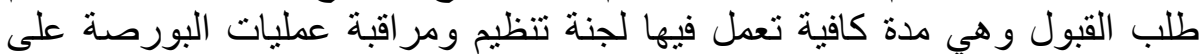

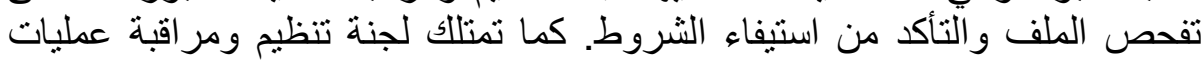

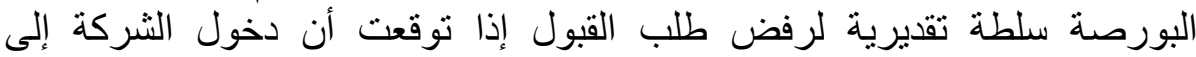
البورصة سيخل بالسير الحسن للسوق. أضف كذللك إلى أنه طبقا للنصوص التصف القانونية

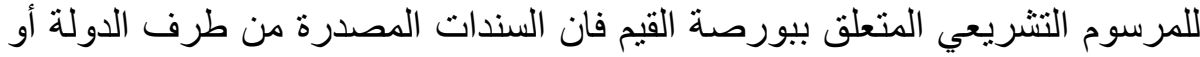

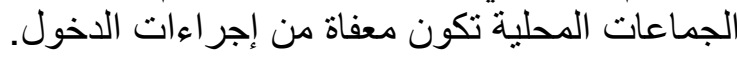

و عموما هناك مجموعة من الثروط التي يجب أن تحققها شركات المساهمة حتى إنى أنى تقبل أور اقها المالية في البورصة.

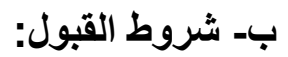

حدد القانون العام (المرسوم التنفيذي رقم 10/93 المؤرخ في 23 مائ 1993) المعايير النالية لتقبل أسهم الثركات الثرم المساهمة في البورصة: 
ـ نشر المراكز المالية المصادق عليها للثناث سنوات السابقة للسنة التي قدم خلالها طلب القبول. - مجن - إثبات وجود هيكل للمر اجعة الداخلية.

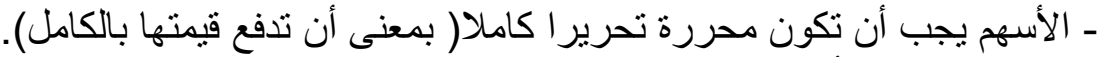
- منمان تحويل الأوراق المالية.

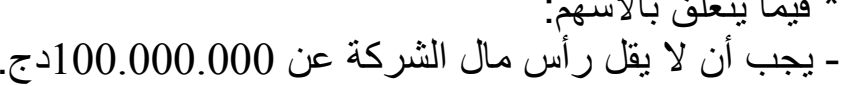
- يجب أن تطرح الثركة 20\% على النى الأقل من ر أسمالها للاكتتاب لدى الجمهور .

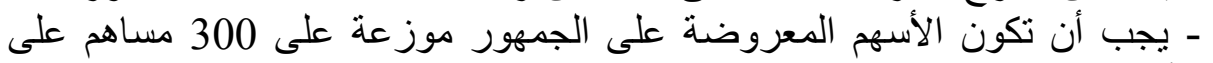
الأقل يوم الدخول إلى البون الأبور البعة

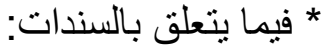

- مبلغ القرض يجن بالبندات أن يكون مساوي على الأقل ل 100.000.000 دج. - يجب أن يكون عدد الحائزين للسندات 100 حائز على الأقل يوم الاخول الألى إلى

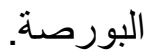
عندما تستوفي الثركة شروط القبول، يجب عليها أن تحضر ملف القبول الذي

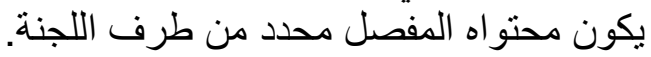
ج- إجراءات الاخول إلى البولى البورصة:

طبقا لأحكام المادة 18 من المرسوم التشريعي رقم

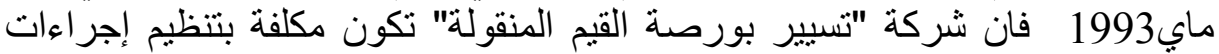
الاخول، وفي هذا الاتجاه فان القانون العام يحدد ثلاثة نماذجة أو أنواع من الإجر اءعات

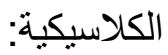
ـ الإجراء العادي، بطبق على الأوراق المالية الثبيهة بالأوراق المسعرة من قبل،

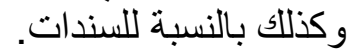

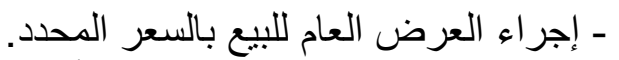
- إجراء العرض العام للبيع بالسعر الأدنى.

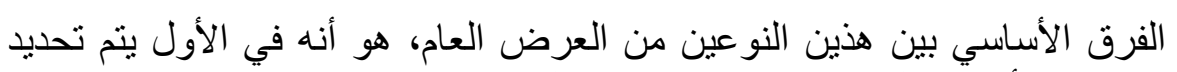

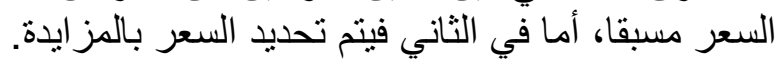

يتكفل القانون العام للبورصة بتحديد طرق أو كيفيات إعلام الجمهور عند الجيد الاخدول

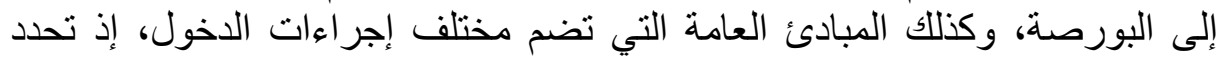
"شركة تسبير بورصة القيم"الطرق العملية لسير هذه الإجر اءعات.

كما تجدر الإشارة إلى أن الأمر

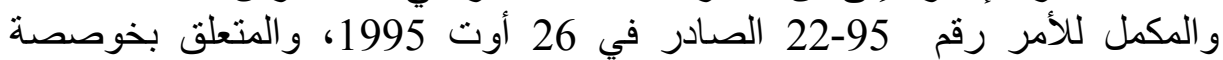
المؤسسات العمومية قد نص على ما يلي: 
1- أن المؤسسة التي تقوم بتنفيذ عملية الخوصصة مكلفة بأن تقدم للحكومة إجر اءات

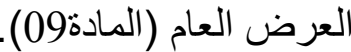

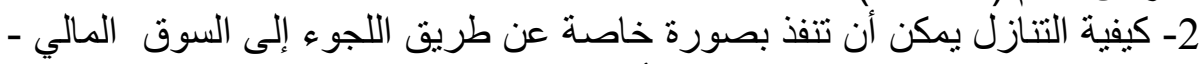

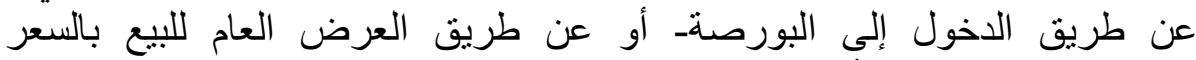
المحدد(المادة15) هذا الأخير الذي سيقتصر على عدد محدود من المستثمرين.

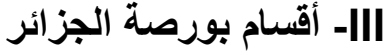

تتكون بورصة الجزائر من قسمين رئيسيين:

1- قسم القيم المنقولة: يتم التداول في هذا القسم على سندات رأس المال وسندات

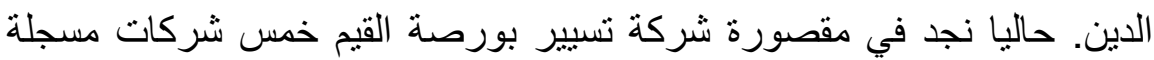

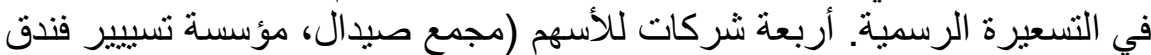

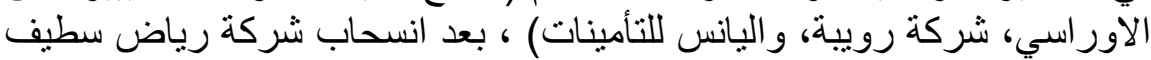

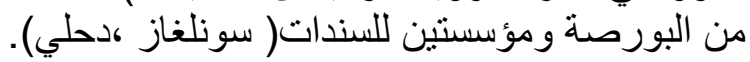

2- قسم سندات الخزينة العمومية: في إطار الإصلاحات الإن المبذولة من طرف وزارة المالية والتي ترمي إلى إعادة الاعتبار إلى السوق المالي التي في عملية تمويل

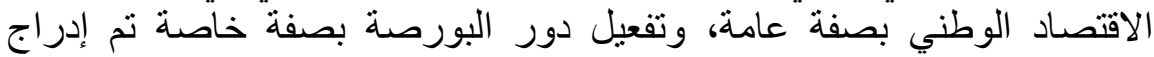

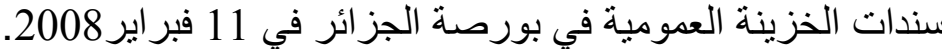

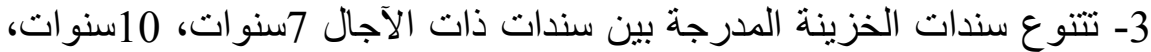

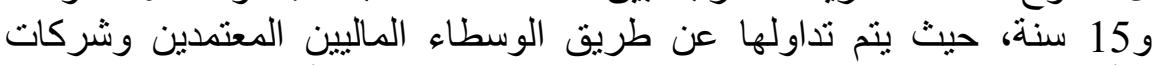

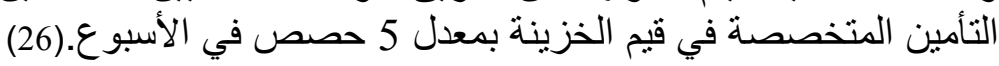

\section{- تحليل وضعية بورصة الجزائر -VI}

سيتم تحليل وضعية بورصة الجز ائر من خلال مجموعة من المؤشر ات:

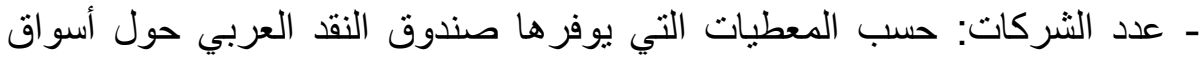

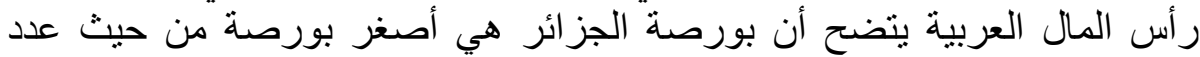

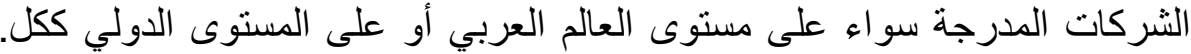
بستة شركات (أربعة شركات طرحت أسهما بعد أنسحاب شركة الرياض الف سطيف،

$$
\text { وشركتين طرحت سندات). }
$$

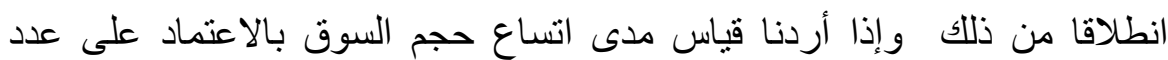

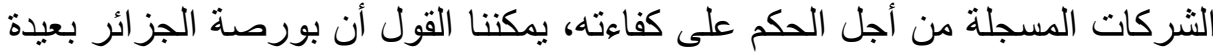

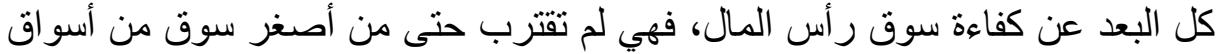

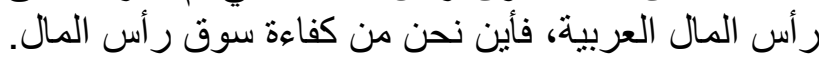

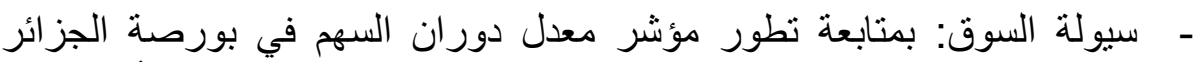

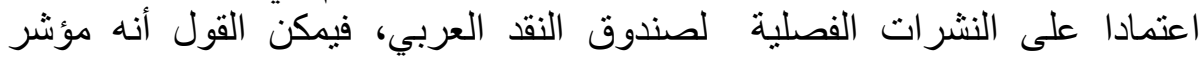


ضعيف جدا يدل على انخفاض تداول الأسهم في بورصة الجزائر، حيث يقل معدل

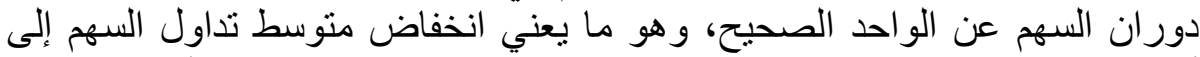

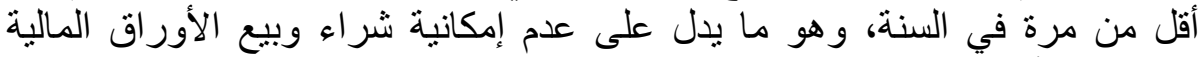

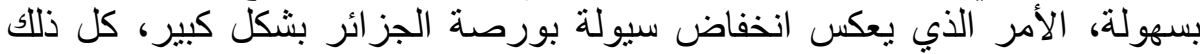
يجعلنا نستنتج أن بورصة الجزائر تعرف الخفاض ركودا في نشاطها كما أنها تنمو بمعدل كبرل بطئ جدا . - رأس المال السوقي: بشكل عام عرف رأس المال السوقي في الجزائر انخفاضا

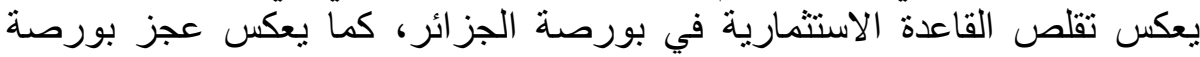

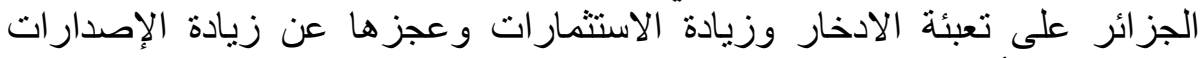

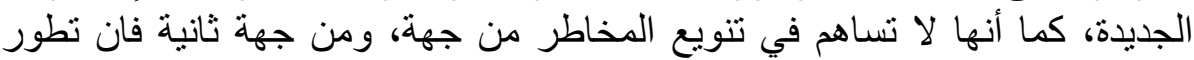

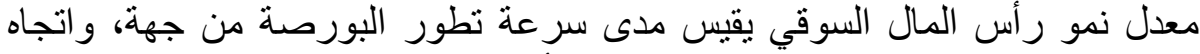

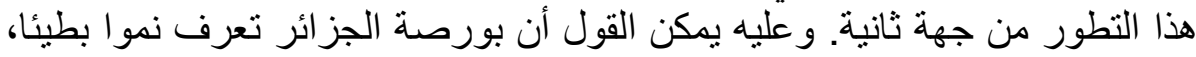

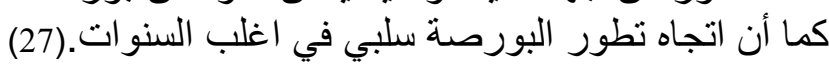

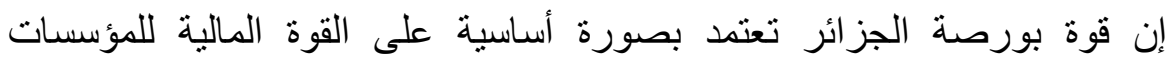

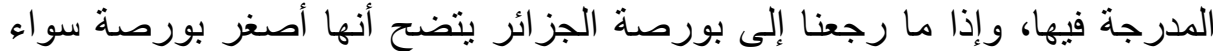

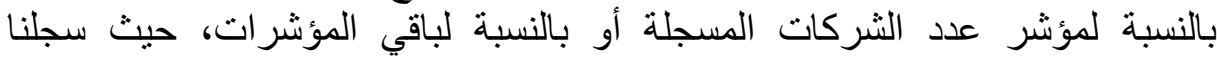

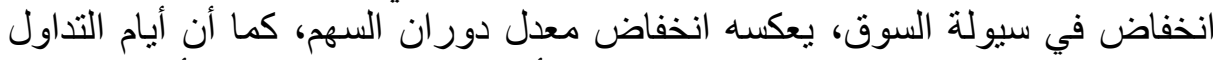

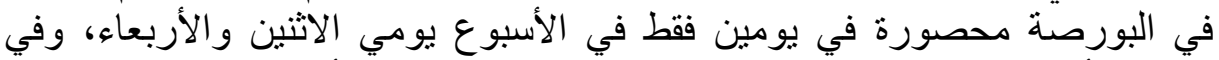

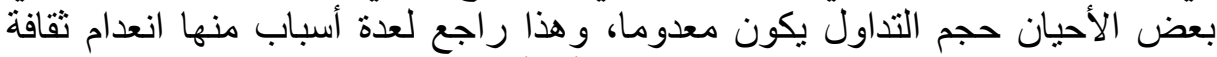

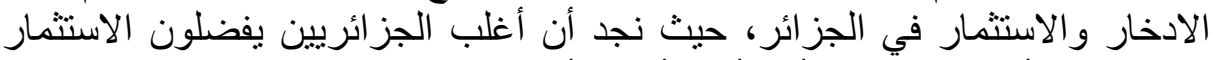

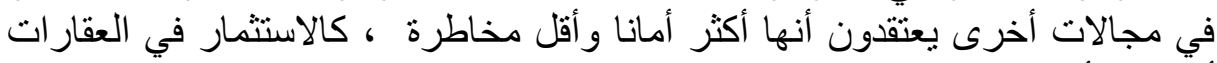

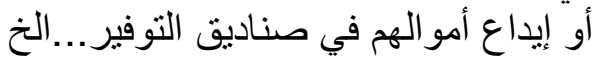

كما كانت البورصة لفترة من الزمن مفهوم دخيل على المجتمع الجزائري، وهي الجي الجئي

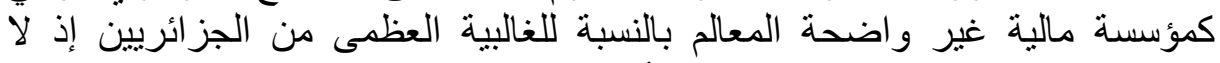

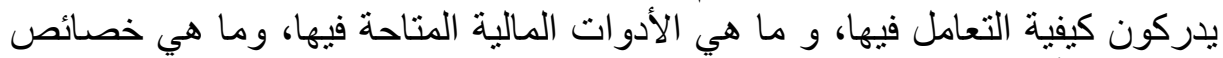
ومز ايا كل أداة، هذا بالنسبة للفرد.

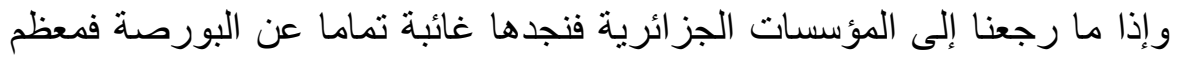

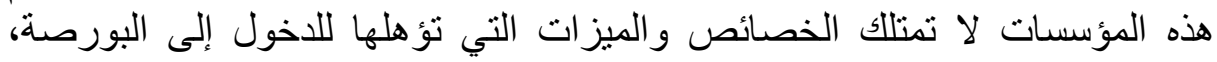

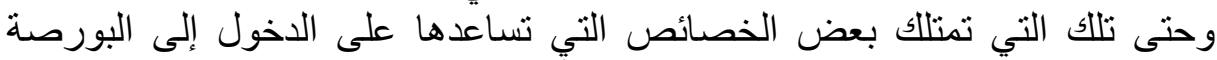

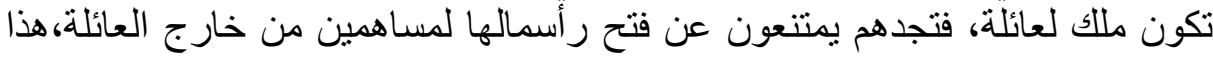
من جهة، ومن جهة ثانية لا يمكننا إنشاء بورصة فئة تحركها المؤسسات العمومية فقط، العانة و إلا فما الهدف من ودن جها إنشائها.

كما أن البورصة لا يمكن أن تنمو وتتطور دون مؤسسات خاصة، الذاذ اذ تعتبر البورصة وسيلة لتحقيق الخوصصة، هذه الأخيرة التي تلعب دورن دورا هاما في تحقيق 
التتمية الاقتصادية، كما أن البورصة تعد وسيلة أساسية لتمويل الجهاز الإنتاجي. بينما أكد المدير العام لبورصة الجزائر بأن 85\% من الثركات النات الخاصة في

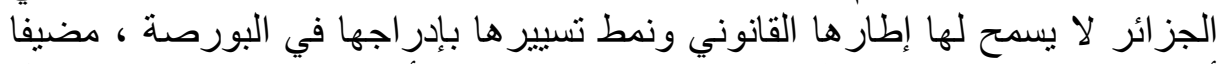

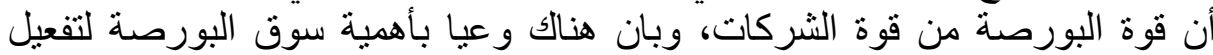
الاقتصاد الوطني، كما أن الهدف من إنشاء البورصة كان كان مواكبة عملية الخوصدانة

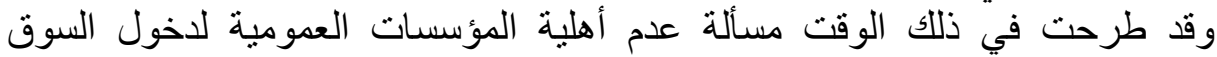

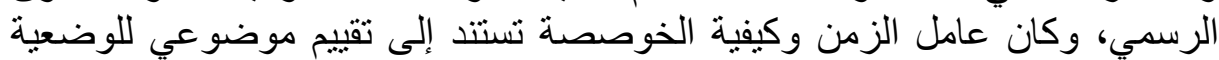

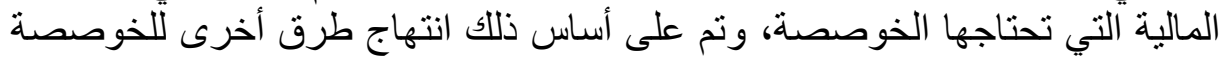

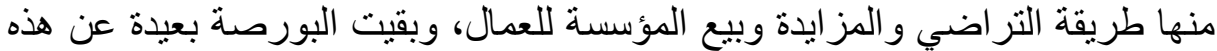

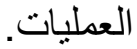

أما فيما يخص النشاط العام لبورصة الجزائر شهذ نشاط قاعة التداول لبورصة الجزائر انخفاض خلال شهر أوت2015 حيث بلغت قيمة المعاملات 1200931 دج، مسجلة بذلك تراجع قدره 18 , 18 ، مقارنة بالثهر الماضي أين سجلت التداولات ما قيمته 2558265 دج .كذللك انتقل حجم التداول من(321 12 أسهم وسندات) في شهر جويلية إلى 4762 في شهر أوت مسجلاً بذلك نسبة انخفاض

قدر ها 78.30\%. (28) - (28)

مؤشرات نشاط بورصة الجزائر اوت 2015

\begin{tabular}{|c|c|c|c|}
\hline التغير\% & اوت2015 & جويلية2015 & البيانات \\
\hline- & 9 & 9 & عدد ايام التداول \\
\hline 44.84 & 323 & 223 & عدد الاو امر \\
\hline 2.41 & 82976 & 81022 & حجم الاو امر المعروضة للشر اء \\
\hline 48.01 & 357816 & 241736 & حجم الاو امر المعروضة للبيع \\
\hline$-81,24$ & 1093120 & 5826255 & قيمة التداول (دج) \\
\hline$-78,30$ & 2673 & 12321 & حجم التداول \\
\hline$-52,94$ & 8 & 17 & عدد الصفقات \\
\hline$-25,19$ & 0.89 & 1,89 & المعدل اليومي للصفقات \\
\hline$-19,52$ & 121457.78 & 647361,67 & 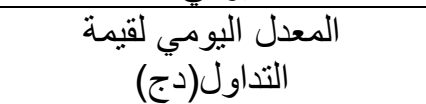 \\
\hline$-78,30$ & 297 & 1369 & المعدل اليومي لحجم التداول \\
\hline
\end{tabular}

Source: http://www.sgbv.dz/ar/?page=rapport\&rap=2/23/10/2015 18:04 نلاحظ من خلال مؤشرات الجدول أعلاه ، أن عدد أيام التداول بقي على حاله 
خلال شهري جويلية وأوت وهو 9 أيام، في حين تم تسجيل ارتفاع في كل من حجم الاوامر المعروضة للشراء، و حجم الاوامر المعروضة للبيع قدر ب 2.41\% و 48.01\% على التوالي. بينما انخفضت قيمة التداول،حجم التداول و عدد الصفقات

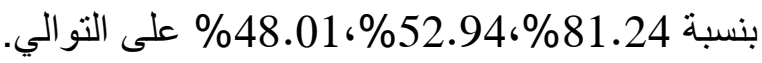

كما انخفض المعدل اليومي للصفقات ب 25.19\%، و المعدل اليومي لقيمة التداول ب 19,52\% ، بالإضافة إلى تسجيل انخفاض واضح في المعدل اليومي لحجم التداول قدر ب78.30\%، كل هذه الأمور تعكس ضعف نشاط بورصة الجزائر.

مؤشرات اسعار بورصة الجزائر اوت 2015

\begin{tabular}{|c|c|c|c|c|}
\hline المتوسط (دج) & السعر(دج) معدل & أدنى سعر(دج) & أعلى سعر(دج) & والسندات \\
\hline & & & & الأسهم \\
\hline 572,50 & 570 & 570 & 570 & البانس للتامينات \\
\hline 440.00 & 440 & 440 & 440 & الاور اسي \\
\hline 375,00 & 378,89 & 375 & 380 & ان سي أرويية \\
\hline 580,00 & 572,78 & 565 & 605 & صبدال \\
\hline & & & & السندات \\
\hline $100 \%$ & $100 \%$ & $100 \%$ & $100 \%$ & داحلي 2016 \\
\hline
\end{tabular}

Source: http://www.sgbv.dz/ar/?page=rapport\&rap=2/23/10/2015 18:04 يتضح من مؤشرات الجدول أعلاه بقاء أسعار اغلب الأسهم ثابتة دون تغيير وهو التها

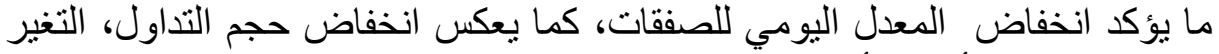

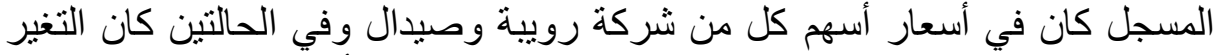
نحو الانخفاض، وفي كلا الحالتين هو مؤشر سلبي عن أداء أداء البورصة من جهة و الثركات المدرجة من جهة ثانية.

V - جديد البورصة والخوصصة في الجزائر

من المستجدات التي تخص البورصة و الخوصصة "أن وزارة المالية بصدد إعداد

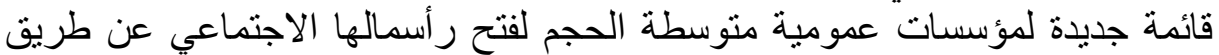

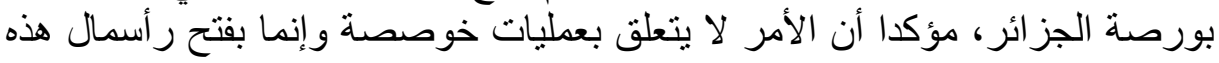


الثركات بنسبة لا تتجاوز 20\% ، وبالرغم من تصريح وزير المالية إلا أن هذه العملية تبقى تصنف من قبل الخبراء الاقتصاديين ضمن أثكال الخوصصة الجية الجزئية

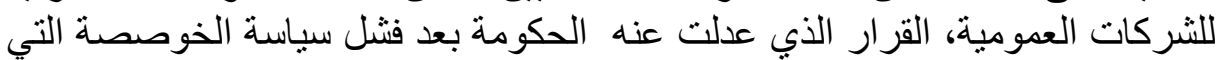

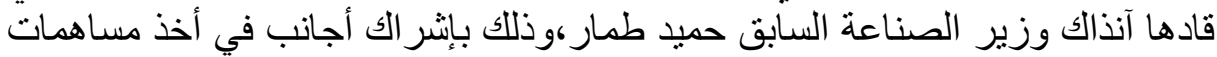

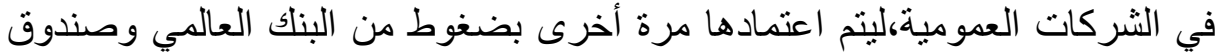

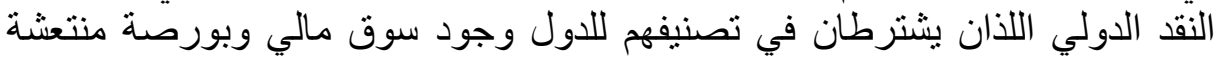
لتمويل استثمار ات المؤسسات.

وقد أوضح وزير المالية على هامش الملتقى المنظم بفندق الاوراسي من قبل لجنة مراقبة ومتابعة عمليات البورصة بتاريخ 25 افريل 2013 حول "مزايا الدخول

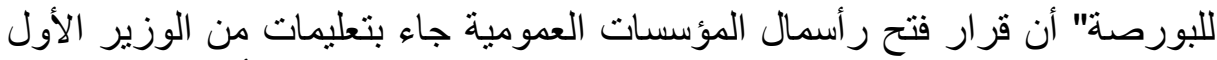

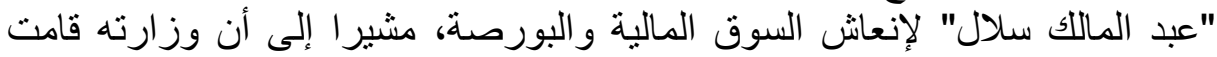

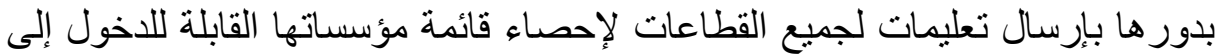

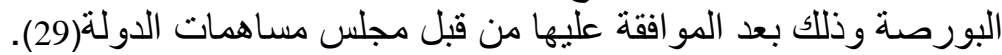

وبالفعل فقد منح مؤخرا مجلس مساهمات الدولة الضوء الأخضر لاخول 10

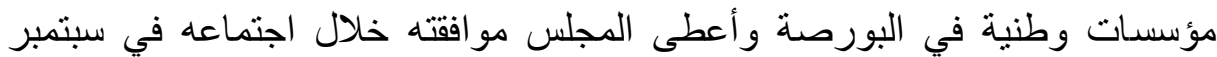

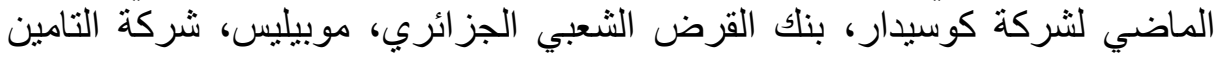
caar باعتبار ها الأكثر ربحية والر ائدة في قطاعها) (30).كما تهدف الحكومة إلى إدخال 40 شركة عمومية في البورصة قبل نهاية 2015.

وكانت وزارة المالية قد أقرت السنة الماضية إجراء تتظيم ينص على مراجعة

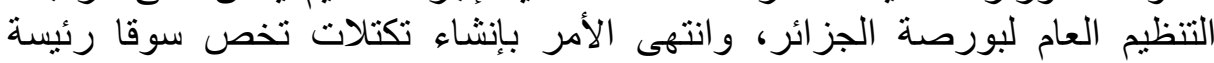

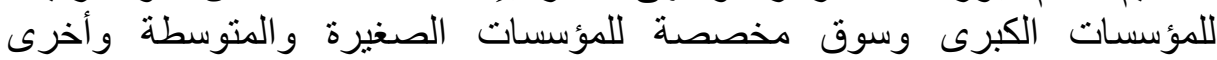
مخصصة لسندات الخزينة.

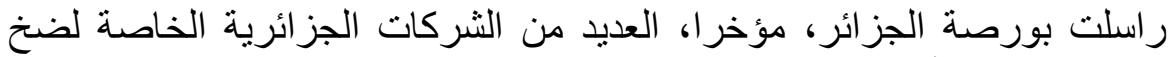

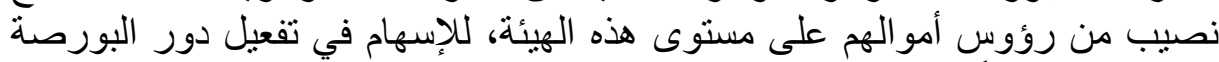

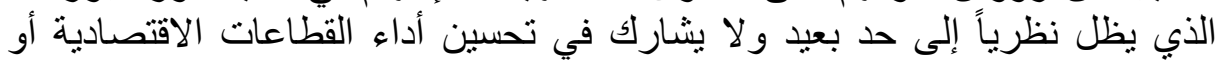

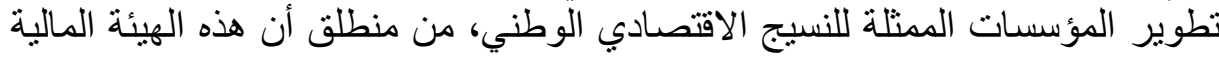

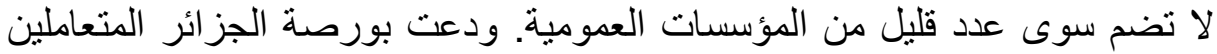

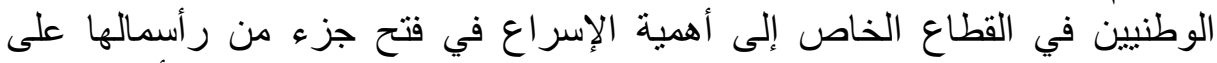

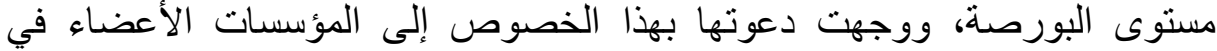

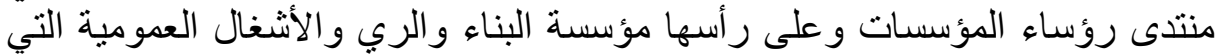

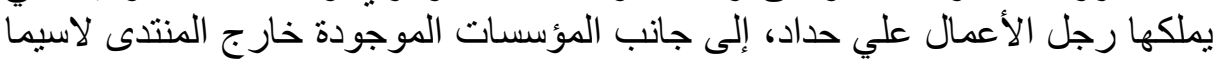




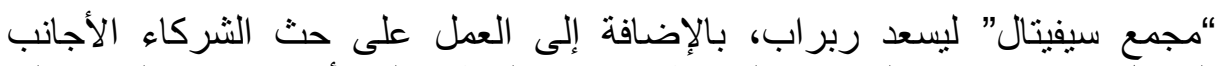

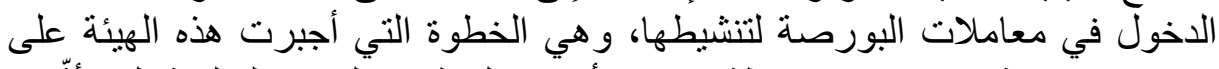

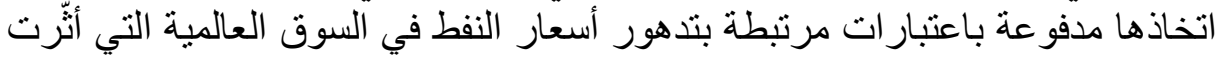

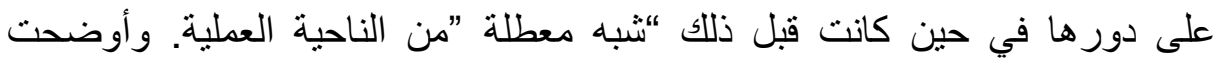

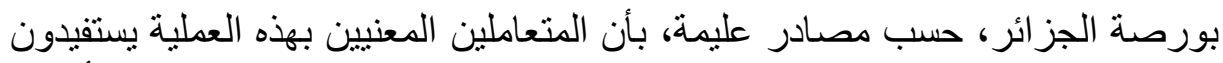

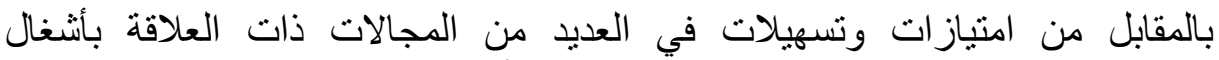

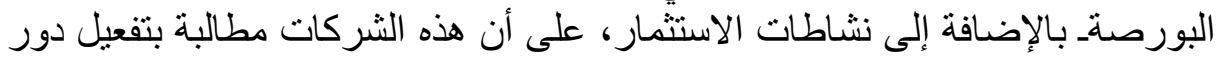

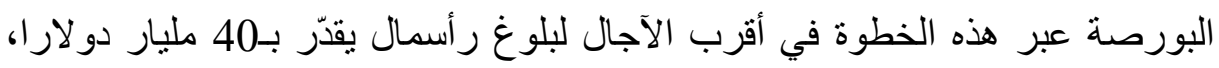

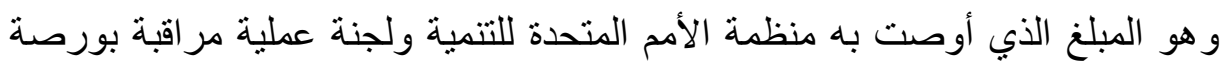
الجزائر .وتوجهت بورصة الجزائر خلال بضعة أشهر نحو استر اتيجية جديدة لتنشيط

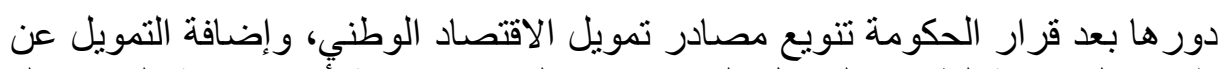

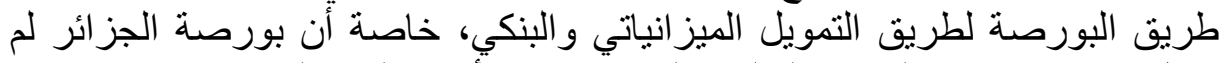

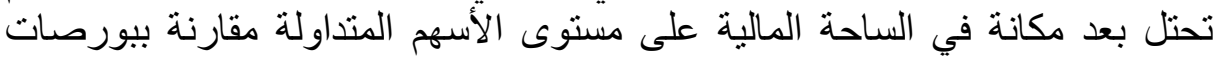

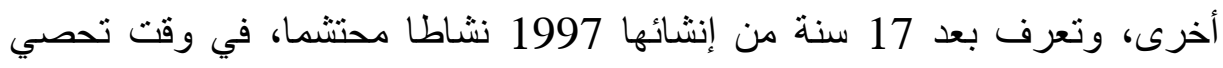

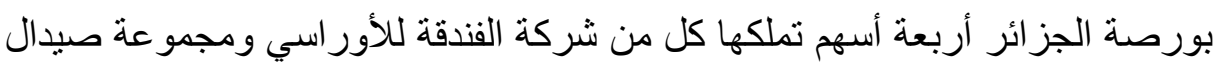

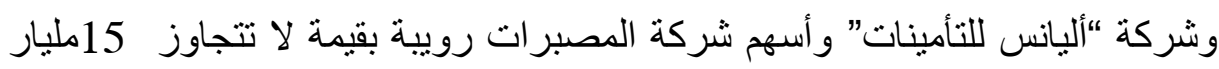

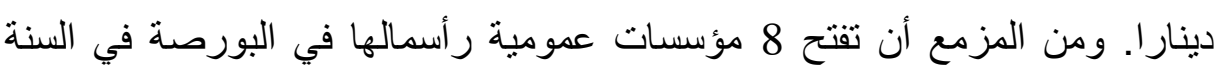
الجارية، بعد أن تتم المصادقة على هذه العملية من طرف مجلس مساهمات الدولة.

\section{الخاتمة}

تعتبر الخوصصة حجر الأساس في بناء البورصة أو الدافع الأساسي لإنشائها، لأن

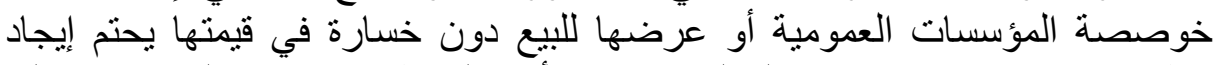

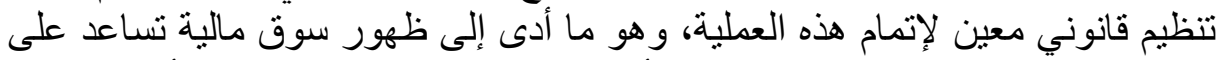

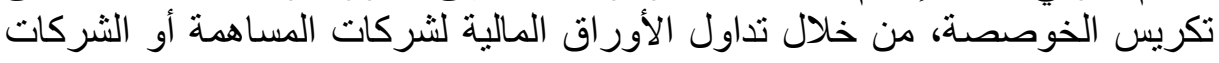
المدرجة بشكل عام.

كما أصبح تطوير سوق رأس المال يعد من الأهداف التي تسعى الحكومات إلى إلى إلى إلى

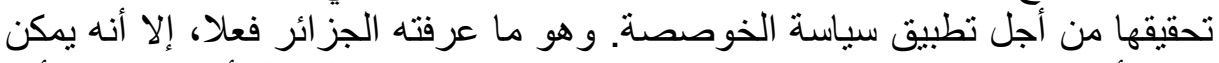

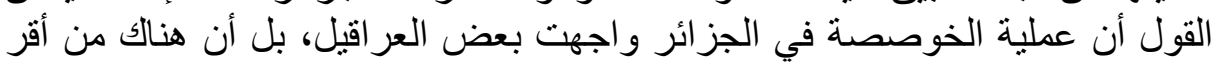

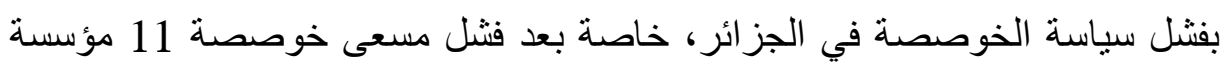

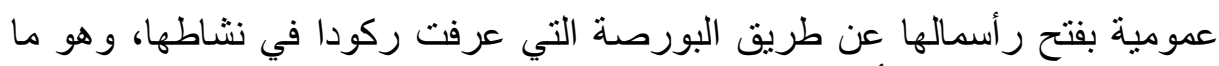
جعل الدولة تتنخل من أجل نسهيل دخول عدد من المؤسسات إلى البورصة ونت فئنيع 
تداول أسهمها لتحسين أسعار ها.

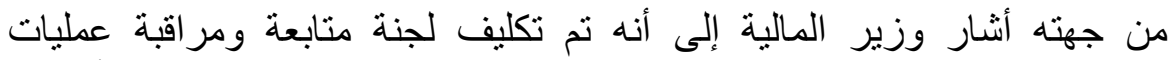

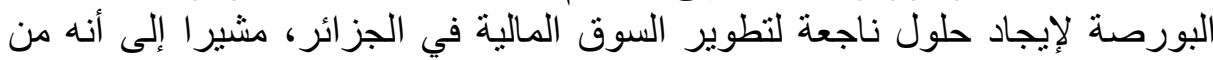

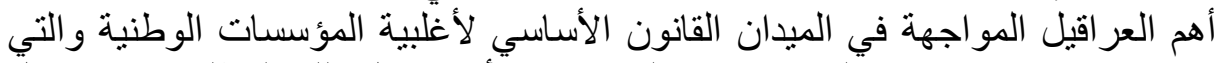
تعتبر شركات ذات مسؤولية محدودة وليست ذات أسهر منل تلاتك المطلوبة في تمويل

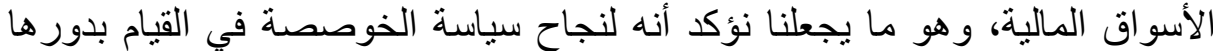

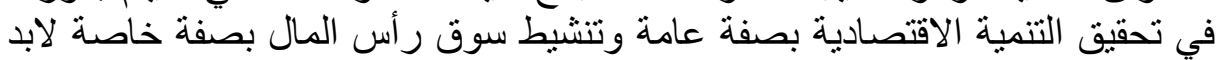
من تكاثف الجهود و اتخاذ جملة من التدابير و الإجر اءات اتصنة التصحيحية منها:

- وضع تحفيزات تشجع المؤسسات على فتح رأسمالها وطرح أور اقها المالية في

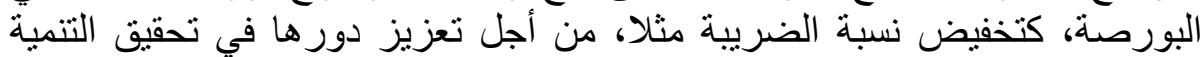

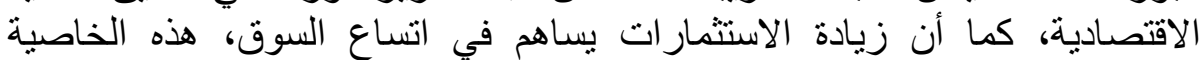

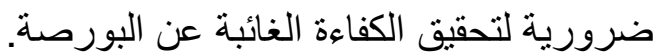

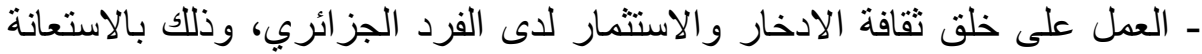

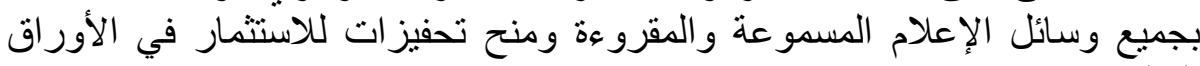

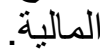
- إعادة النظر في هيكلة البورصة من أجل تحديد نقاط القوة ونقاط الضعف ومحاولة

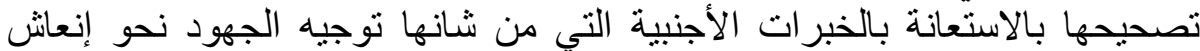

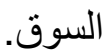
- إعادة النظر في تشريعات السوق لتحقيق الأمان للمتعاملين، خاصة المواطن

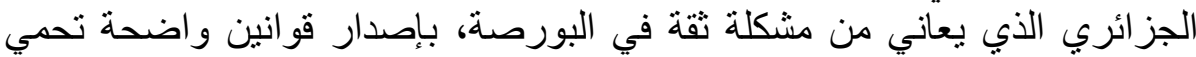
المتعاملين وخاصَة صنغار المستثمرين منهر.

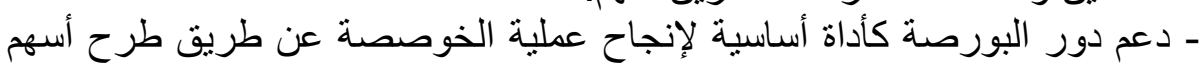
الثركات العمومية للاكتتاب العام. دوران.

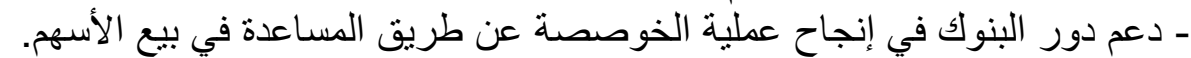

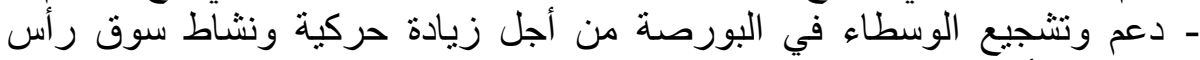

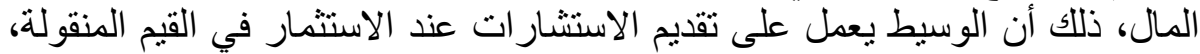

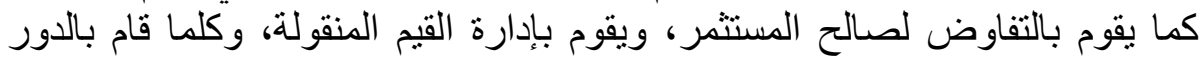

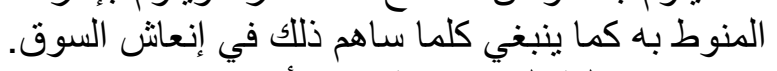

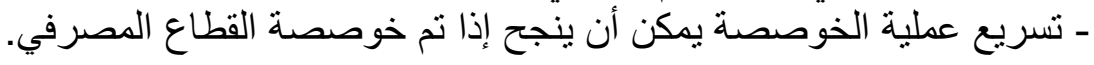




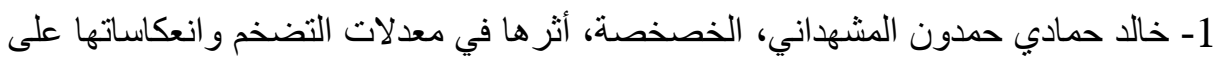

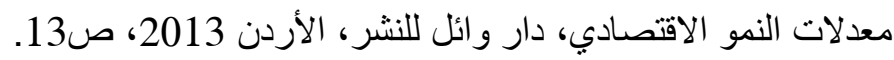

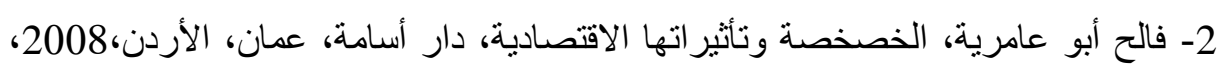
ص9. (n)

3- ليث عبد الله القهيوي، بلال محمود الوادي، التحول من القطاع العام إلى القطاع الخاص،

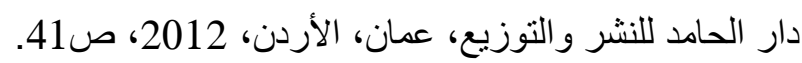

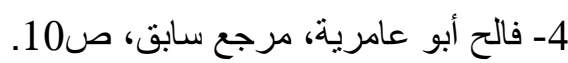

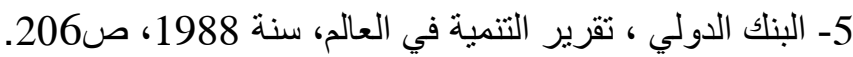

6-http://centeruniversitair-d.Forum-him.com/t33-topic. 5 /11/2013. 17 :00 7- http://www.startimes.com/F,aspx?t=29468613. 12 /11 /2013

$$
\text { 8- ليث عبد الله القهيوي، بلال محمود الو ادي، مرجع سابق، ص45/2013/ } 5 \text {. }
$$

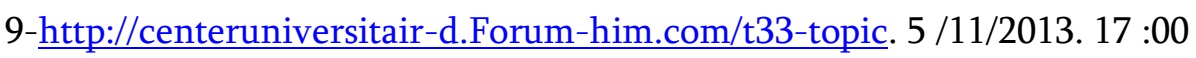
10-http://centeruniversitair-d.Forum-him.com/t33-topic.5 /11/2013. $17: 00$ 11- http://www.ibndz.com/vb/ibndz52244. 5/11/2013 13 :30

12- http://www.tassilialgerie.com/vb/showthread.php?t=5626. $04 / 11 / 2013$ $19: 40$

13- http://www.ibndz.com/vb/ibndz52244. 5/11/2013 $13: 30$

$$
\text { 15- فالتح أبو عامرية، مرجع سابق، ص ص 39 39، 40. }
$$

16- رياض دهال وحسن الحاج، حول طرق الخوصصة، تجارب بعض الدول النامية، مجلة

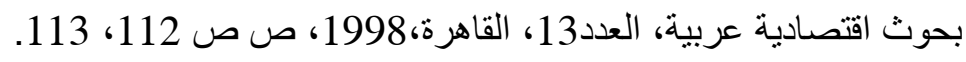

17-http://www.ibndz.com/vb/ibndz52244 .5/11/2013 $13: 30$

$$
\text { 18- فالح أبو عامرية، مرجع سابق، ص ص 18، } 19 .
$$

19- ليث عبد الله القهيوي، بلال محمود الو ادي، مرجع سابق، ص53.

20- لطرش سميرة، كفاءة سوق رأس المال و أثر ها على القيمة السوقية للسهم، دراسة

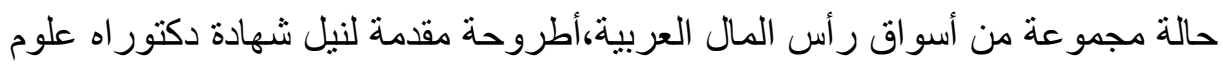

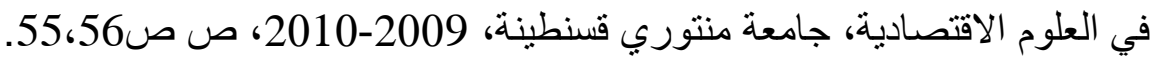


21- شمعون شمعون، بورصة الجزائر، أطلس للنشر، الجزائر، د س ن، ص ص

$$
.80 ، 79
$$

22- شمعون شعون، مرجع سابق، ص 80.

23- www.sgbv.dz. 17/11/2013 $19: 30$

24- www.sgbv.dz. 17/11/2013 $20: 00$

25- commission d'organisation et de surveillance des opération de bourse(COSOB), l'introduction en bourse ,condition et modalités, avril 2001,p 1.

26-www.sgbv.dz. 17/11/2013 $21: 00$

$$
\text { 27- لطرش سميرة ، مرجع سابق، ص ص 276، } 280 .
$$

28- http://www.sgbv.dz/ar/?page=rapport\&rap=2/23/10/2015 18:04

29-www.elkhabar.com/ar/économie. 11/12/2013 17 :05

30- www.elmihwar.com/index.php/économie. 11/12/2013 16 :30

h31-www.elkhabar.com/press/article/15316/\%D8\%A8\%D9\%88\%D8\%B1\% / 23/10/2015 $19: 47$

$$
\text { - القوانين والتشريعات }
$$

ـ قانون 88-16 المؤرخ في 12- 01-1988 المتعلق باستقلالية المؤسسات.

ـ المرسوم رقم 91- 169 المؤرخ في 28-05-1991، المتعلق بتنظيم المعاملات الخاصة بالقيم المنقولة.

ـ المرسوم رقم 91-170 المؤرخ في 28 - 05-1991 ، المتعلق بالقيم المنقولة

$$
\text { وشروط إصدار شركات المساهمة لها. }
$$

- المرسوم رقم 91-171- المؤرخ في 28- 05-1991 الخاص بلجنة بـنة تنظيم ومر اقبة عمليات البورصة (COSOB).

- المرسوم رقم 93-08 المؤرخ في 25-04-1993 الخاص بالأحكام المتعلقة بشركات المساهمة. ـ المرسوم رقم 93-10 المؤرخ في 23-05-1993 المتعلق ببورصة القيم. 
سياسة الخوصصة وأثرها على بورصة الجزائر

ـ الأمر رقم 95- 22 المؤرخ في26- 08-1995 المتعلق بخوصصة المؤسسات

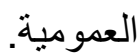

